\title{
THE EFFECTS OF ALTERNATE SUCTION AND PRESSURE ON BLOOD FLOW TO THE LOWER EXTREMITIES
}

\author{
By EUGENE M. LANDIS ANd JOHN H. GIBBON, JR. \\ (From the Robinette Foundation of the Hospital of the University of \\ Pennsylvania, Philadelphia)
}

From the therapeutic standpoint patients with peripheral vascular disease are divided into two groups, (a) those whose symptoms are due to simple spasm with no, or very slight, organic vascular obstruction and $(b)$ those whose symptoms are due primarily to advanced organic disease of the arteries. The symptoms of the first group can usually be alleviated by producing vasodilatation with drugs, diathermy, local heat in the form of the warm cradle, or sympathetic ganglionectomy. The efficacy of these therapeutic procedures depends upon local dilatation of the peripheral blood vessels.

In more advanced stages, however, obliterative structural disease has usually progressed until the arterial vessels are transformed into rigid tubes. These diseased vessels have not only abnormally small lumina but are also more or less incapable of dilatation even when vasomotor tone is reduced by nerve block or by sympathetic ganglionectomy. When the arteries have thus lost their power of dilating the therapeutic procedures mentioned above fail to increase blood flow and therefore fail to improve the nutrition of the tissues. Eventually many of these patients with advanced organic disease of the arteries suffer from trophic changes, ulceration and gangrene, leading finally to amputation. Any procedure which tends to increase blood flow in the presence of organic occlusion might be of benefit in delaying or possibly in preventing the appearance of gangrene.

According to Poiseuille's law the amount of fluid flowing through a rigid tube depends upon the fall in pressure along the tube. If other factors remain constant doubling the peripheral fall in blood pressure should approximately double the amount of blood flowing through the rigid arterial vessels. The total fall in pressure in the peripheral vascular system may be increased in two ways, $(a)$ by elevating systemic blood pressure or $(b)$ by diminishing capillary and venous blood pressures. The first method is impracticable for numerous reasons. It seemed possible, however, that capillary and venous blood pressures might be reduced temporarily to negative values (i.e., below atmospheric pressure) by applying suction to the skin of the extremity.

The full effect of externally applied negative pressure can only be .obtained if there be a reservoir capable of accommodating the blood which 
has flowed through the narrowed arteries. The capillaries and veins, when not constricted, offer such a reservoir-of limited capacity. Landis and Gibbon (1) observed that inflating a pneumatic cuff on the upper arm to a pressure of $30 \mathrm{~cm}$. water for 5 minutes increased the volume of a segment of forearm by $25 \mathrm{cc}$. of which $3 \mathrm{cc}$. consisted of extravascular fluid while $22 \mathrm{cc}$. consisted of blood trapped in the congested peripheral vessels. Similarly, a venous pressure of $60 \mathrm{~cm}$. water during 6 minutes increased the volume by $38 \mathrm{cc}$. of which $7 \mathrm{cc}$. was extravascular fluid and $31 \mathrm{cc}$. was blood in the congested vessels. The total volume of the segment of forearm was $720 \mathrm{cc}$. so that at pressures of 30 and $60 \mathrm{~cm}$. water the reservoir available was 3 and $4 \mathrm{cc}$. per $100 \mathrm{cc}$. of arm respectively. Average blood flow in the normal forearm amounts usually to less than $5 \mathrm{cc}$. per minute per. $100 \mathrm{cc}$. of tissue (Lewis and Grant (2)). Hence, with a slight rise of pressure the veins and capillaries can accommodate the blood flowing through normal vessels during a period of approximately one minute.

From these observations it seemed possible that the periodic application of negative pressure to the surface of the lower extremity might be expected to increase blood flow even though the arterioles had been changed into rigid tubes by reason of structural disease. Moreover, if the suction were applied for relatively short periods of time the efficiency of the method would be greater since the available reservoir would not be filled to capacity during any one suction period. The accumulation of blood in the capillaries and veins must lead to stretching of their walls, the resistance to further distention increasing as the amount of trapped blood becomes greater. This resistance would, of course, lessen the effect of external suction on the peripheral drop in blood pressure particularly if suction were prolonged. It seemed essential, therefore, not only to use relatively brief periods of suction but also to empty the capillary and venous beds of their contained blood after each brief suction period, so that space might be available for the accommodation of fresh arterial blood to be drawn in during the succeeding suction period. Therefore, suction and pressure were applied alternately.

The effects of alternate suction and pressure on flow have been studied in a circulatory schema, and in the lower extremities of normal subjects and of patients with peripheral vascular disease. This paper provides objective evidençe that blood flow can be increased by this means. The clinical value of this procedure will be considered in later publications. It seemed advisable first to demonstrate objectively, and under controlled conditions, the correctness of the working hypothesis.

\section{APPARATUS AND METHOD}

A box was made of welded sheet aluminium, reinforced at the sides to withstand pressures between $120 \mathrm{~mm}$. $\mathrm{Hg}$ above and below atmospheric pressure. Aluminium was used to favor radiation of heat since qualitative changes in blood flow were estimated by recording the changes in skin temperature. The box 
was $28 \mathrm{~cm}$. wide, $75 \mathrm{~cm}$. long, $28 \mathrm{~cm}$. high at the proximal end, and $34 \mathrm{~cm}$. high at the distal end. These dimensions permitted the lower extremity to be inserted to a point approximately 8 inches above the knee joint (Fig. 1). The upper

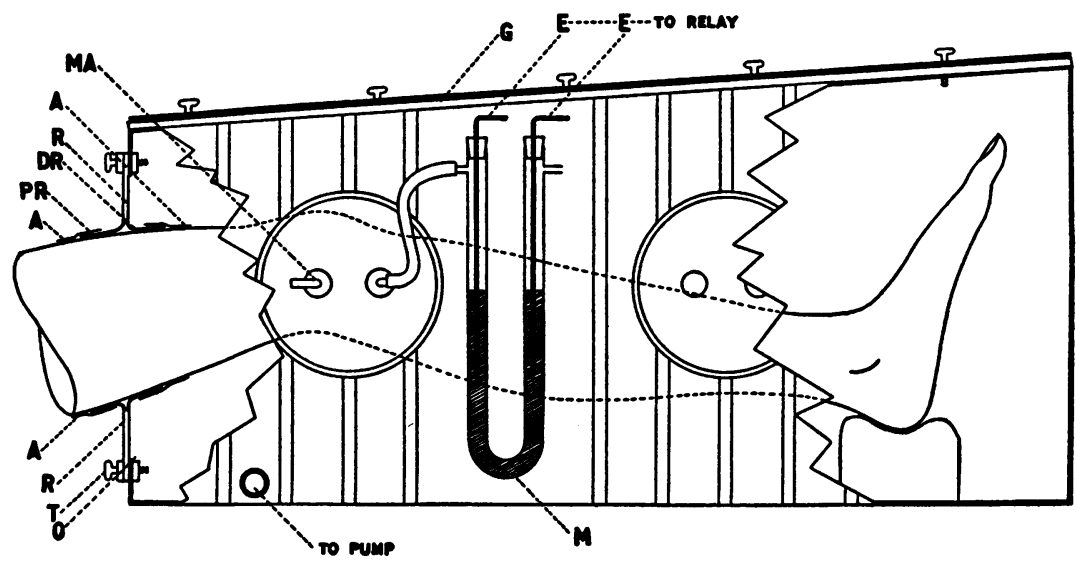

Fig. 1. Diagram of Aluminium Box Used to Apply Suction and Pressure to the LoWer Extremity

For description see text.

surface of the box could be removed and consisted of a sheet of shatter-proof glass $(G)$ mounted in a holder which was screwed down upon a rubber gasket. The foot and leg could thus be observed during the application of suction and pressure. The proximal end of the box contained a circular opening $(O)$ measuring $25 \mathrm{~cm}$. in diameter, which was fitted with a rubber cuff, screwed tightly against the end of the box by means of thumb screws $(T)$. The cuff consisted of a semi-rigid ring $(R)$ of rubber and canvas with an external di.. ameter of $28 \mathrm{~cm}$. and an internal diameter of $14 \mathrm{~cm}$. The internal portion of the cuff consisted of two leaves of lighter flexible rubber having a thickness of 1.5 to $2 \mathrm{~mm}$. These leaves were conical in shape, the smaller end of one $(P R)$ being directed toward the hip while the smaller end of the other $(D R)$ was directed toward the knee. The dimensions of the cuff were adjusted for different subjects so that the flexible rubber fitted snugly against the skin of the thigh. The fit was made as accurate as possible in order to avoid both excessive venous congestion and excessive leakage of air. The rubber was held lightly in contact with the skin by adhesive tape $(A)$. The heel rested on a sand bag and for greater comfort the lower thigh was supported by sand bags placed just within the rubber diaphragm.

The interior of the box communicated through three-quarter inch rubber tubing with an air pump of the Crowell type (size 2A) having a capacity of 13 liters per minute at atmospheric pressure. The interior of the box also communicated with a mercury manometer $(M)$ made of glass tubing with an internal diameter of $1 \mathrm{~cm}$. A metal electrode $(E)$ was inserted into each limb of the manometer. These electrodes were connected with a difference of potential and with the coil of an electrical relay. The contacts of the relay operated a one-half horse power A. C. (Westinghouse, Type RV) motor connected by a leather belt to the air pump. A motor-driven, 3-way metal valve placed the box in communication with the intake pipe of the pump for 25 seconds, and with the 
output pipe of the pump for 5 seconds. The manometer and relay therefore controlled automatically (by the positions of the two electrodes in the manometer) the amount of suction or pressure applied, while the valve controlled the duration of the suction and pressure periods.

In all but two of the observations here reported a negative pressure of 120 $\mathrm{mm}$. $\mathrm{Hg}$ was applied for periods of 25 seconds, alternating with a positive pressure of 80 to $100 \mathrm{~mm}$. $\mathrm{Hg}$ for periods of 5 seconds. It required approximately 3 to 5 seconds to change the pressure within the box from -120 to +120 $\mathrm{mm}$. Hg. For observing the final pressures more accurately a second manometer communicated with the interior of the box through a separate opening $(M A)$.

The air expelled by the pump warmed in the process of compression. Since changes in blood flow were detected by recording skin temperature it was necessary to cool the air entering the box during the pressure periods. The air was therefore passed through a honeycomb radiator immersed in water at 6 to $10^{\circ} \mathrm{C}$. This prevented excessive warming of the air surrounding the lower extremity.

Changes in cutaneous blood flow in the lower extremity were measured qualitatively by observing skin temperature. Three copper-constantan junctions passed into the interior of the box through a rubber stopper inserted in the side wall. One junction was fixed to the skin at the base of the nail of the first toe, another junction was similarly situated on the skin of the third toe. Each junction was covered with one layer of adhesive plaster. The third thermal junction was suspended near the foot to record the temperature of the air around the extremity.

Since in these observations increase in blood flow was identified by elevation of skin temperature it was essential to control the observations very carefully. Therefore, while one lower extremity was placed in the aluminium box the other lower extremity was used as a control and inserted into a second box, having the same dimensions and the same general shape as the aluminium box. This control box was fitted with one 10-watt and one 50 -watt lamp, which could be turned on separately or together in order to keep the temperature of the air in the control box always above that of the air in the aluminium box.

Conditions were arranged to favor greater cooling of the extremity exposed to suction and pressure. First, the air temperature in the control box was higher than that in the aluminium box. Second, the air in the control box was still while that in the aluminium box was moving due to alternate removal and introduction of air during suction and pressure respectively. Third, the extremity in the aluminium box was slightly congested by the rubber cuff while the extremity in the control box was not congested, the space between the skin of the thigh and the proximal end of the control box being closed loosely with cotton. The conditions were thus arranged to favor cooling of the experimental extremity as compared to the control extremity, so that if the extremity exposed to suction and pressure became warmer than the control extremity the change might be safely ascribed to increased blood flow.

\section{OBSERVATIONS}

\section{A. The effects of alternate suction and pressure on the flow of water through a circulation schema}

A schema was used merely to determine whether the application of alternate suction and pressure to an elastic reservoir increased the flow of 
fluid through a partially obstructed rigid tube. In the schema various lengths of capillary glass tube simulated an arterial obstruction while a rubber bag simulated the distensible capillary and venous beds. A valve was inserted in the outflow (or venous) tube leading from the bag to simulate the venous valves.

The rate at which water flowed through the system under a pressure of $80 \mathrm{~mm}$. $\mathrm{Hg}$ (109 cm. water) was first measured over several periods of six minutes without pressure variations, i.e., with atmospheric pressure both inside and outside the box. The first column in Table 1 shows the single and average measurements of the outflow in cubic centimeters per minute. Suction $(-120 \mathrm{~mm}$. $\mathrm{Hg})$ was then repeatedly applied to the portions of the schema within the box for varying periods-25, 55, 85, and 115 seconds-with alternate periods of pressure.

Flow was uniformly greater during suction and pressure. The percentage increase in flow is recorded in the right half of Table 1. Suction for 25 seconds and pressure for 5 seconds increased the outflow by 45 to 63 per cent. With longer periods of suction slightly greater increments in flow were observed since the total drop in pressure was increased for a slightly greater proportion of time, relatively less time being wasted in changing from negative to positive pressure.

\section{B. Observations on normal subjects}

1. The effects of suction and pressure on the rate of cooling of the previously warm lower extremity.

At low room temperatures the extremities of normal subjects cool rapidly as a result of peripheral vasoconstriction which serves to conserve heat by diminishing radiation. As shown by Gibbon and Landis (3) when the forearms are immersed in warm water maximal vasodilatation is produced in the lower extremities, and the surface temperature of the digits rises to $32^{\circ} \mathrm{C}$. or more. In this series of observations the subjects were exposed to low room temperatures and maximal vasodilatation was first produced in the lower extremities by immersing the forearms in warm water. The rate at which the lower extremities cooled following such maximal vasodilatation was observed both with and without pressure changes in order to ascertain whether alternate suction and pressure modified the rate of cooling.

The subjects were seated on an examining table with the legs extended horizontally while the back rested against a support at an angle of 45 to $60^{\circ}$. The right lower extremity was placed in the control box, the air in which was kept slightly warmer than that of the aluminium box. The left lower extremity was inserted into the aluminium box through the rubber cuff.

Figure $2 A$ shows the characteristic result obtained when the two extremities were first warmed through peripheral vasodilatation and then 


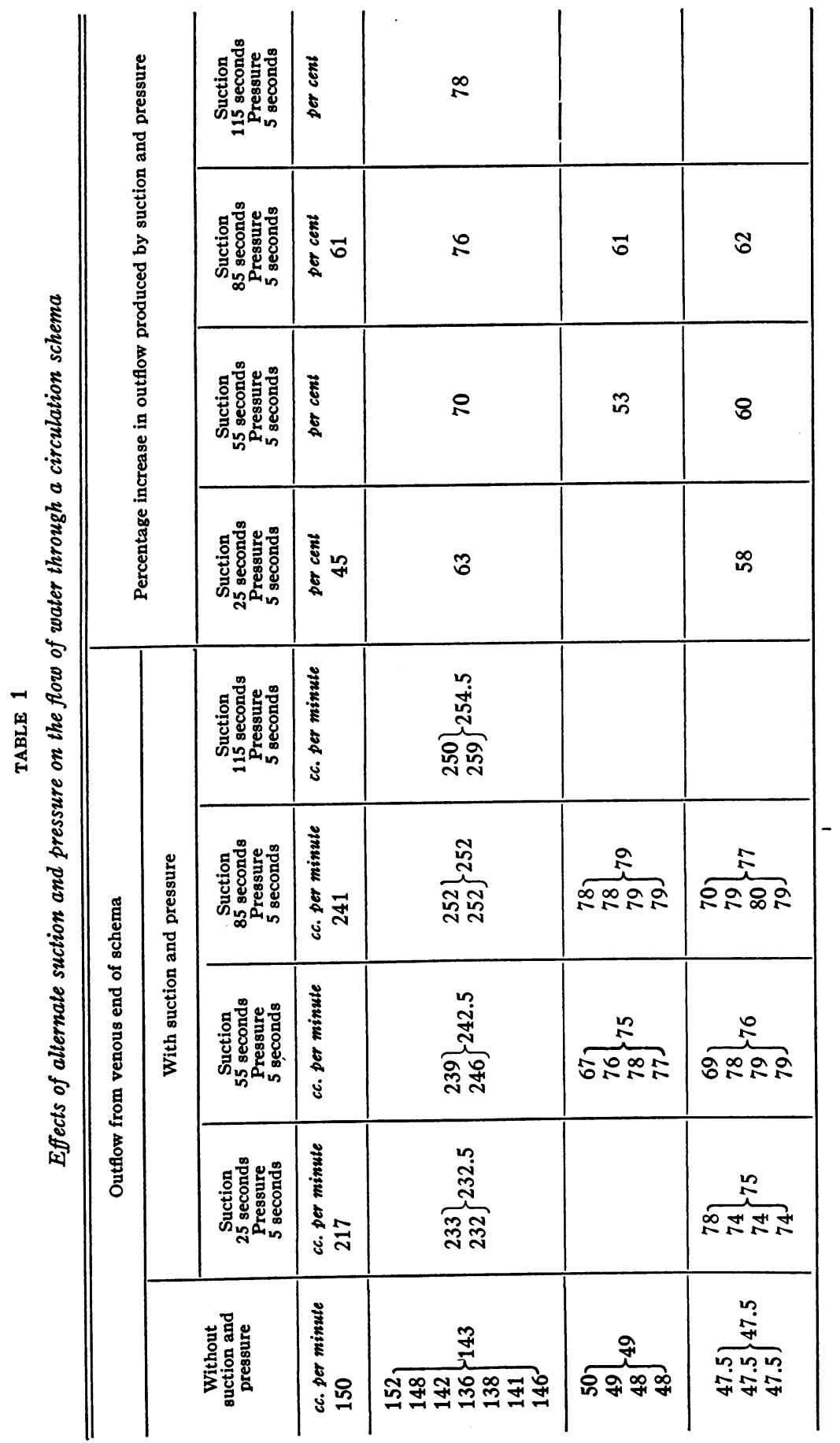




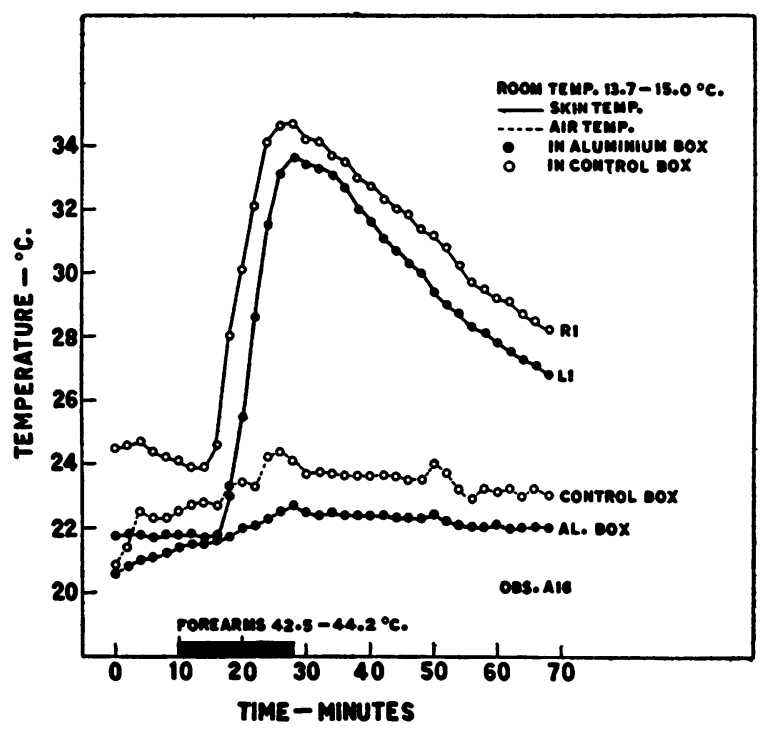

Fig. 2A. Control Observation Showing Cooling of the Digits of the Lower Extremities without Suction and Pressure

In this and subsequent charts $R 1$ indicates the skin temperature of the right first digit, L1 the skin temperature of the left first digit.

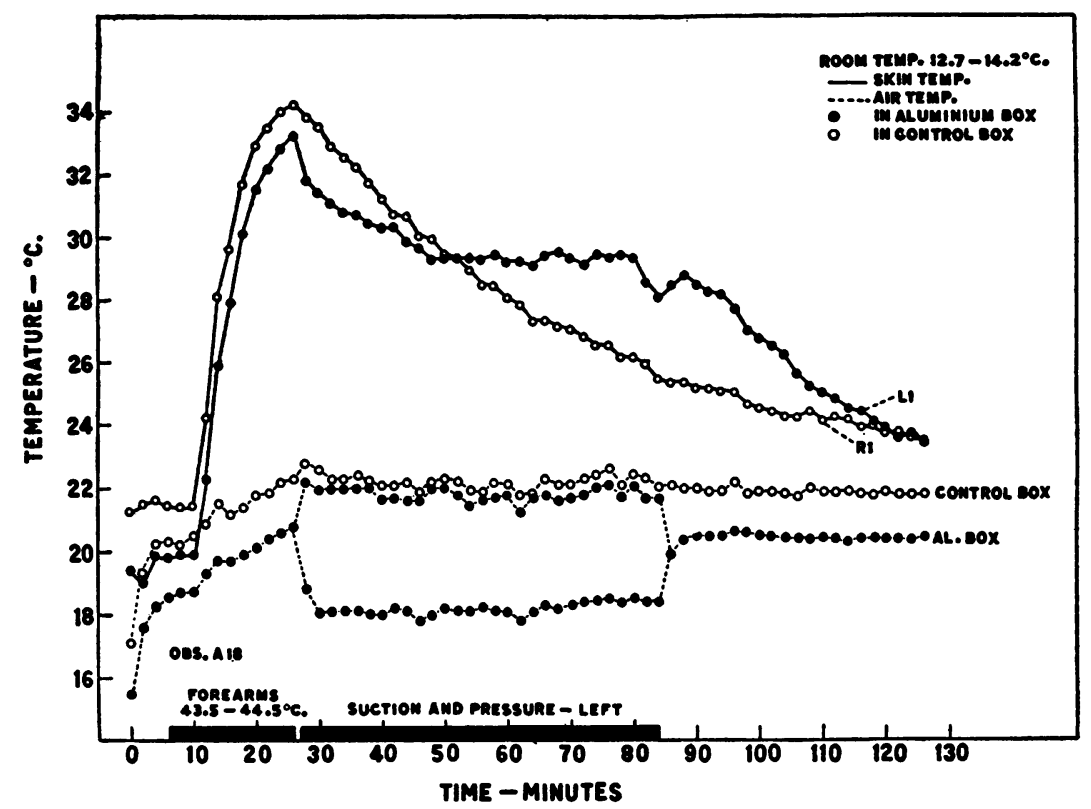

Fig. 2B. Showing Cooling of the Digits during Application of Suction and Pressure to the Left Lower Extremity 
allowed to cool in their respective boxes without suction and pressure being applied to the left lower extremity. As was to be expected, on account of the warmer air in the control box, the temperature reached during vasodilatation was higher in the right extremity. After the forearms were removed from the warm baths vasoconstrictor tone increased and the right and left extremities cooled at approximately the same rate, the right extremity remaining throughout slightly warmer than the left. The subjects were chilly or shivering while the lower extremities cooled.

Six such control observations are summarized in Table 2. Room temperature ranged from 10.7 to $16.3^{\circ} \mathrm{C}$. At the beginning of the cooling period the surface temperatures of the digits were all above $33^{\circ} \mathrm{C}$, the right digits being warmer than the left. The duration of the cooling period varied from 38 to 58 minutes and in this time the temperatures of all the digits became lower. With one minor exception the left digits remained as cool as, or cooler than, the corresponding right digits throughout the cooling period. The temperatures of the air in the aluminium and control boxes were read every two minutes. The figures recorded in Table 2 as "average temperature of air in boxes" at the beginning and end of the cooling periods represent respectively the average of the five readings made during the first 10 minutes and the last 10 minutes of the cooling period. It may be observed that the air in the control box was warmer than the air in the aluminium box by 1.1 to $1.7^{\circ} \mathrm{C}$.

The relation between the surface temperatures of the right and left digits is summarized in the last two columns of Table 2. The temperature of the right first digit at the beginning of the cooling period has been subtracted from that of the left first digit observed at the same time. The left and right third digits have been similarly compared as regards temperature. The minus sign indicates that the left digit was the cooler by the amount given. At the beginning of the cooling period the left digits were from 0.1 to $2.5^{\circ} \mathrm{C}$. cooler than the right. At the end of the cooling period the same relation existed in exaggerated form, the left digits being, with one exception, from 0.0 to $3.8^{\circ} \mathrm{C}$. cooler than the right. The single exception occurred in Observation A16 in which the left third digit became $0.3^{\circ} \mathrm{C}$. warmer than the right third digit. The figures given in the lower right hand corner of Table 2 indicate that the left digits averaged $0.8^{\circ} \mathrm{C}$. cooler than the right at the beginning of the cooling period and $1.8^{\circ} \mathrm{C}$. cooler at the end of the period. These control observations show that, under the environmental conditions mentioned, the left digits remained definitely cooler than the right, when suction and pressure were not applied to the left extremity.

These results are to be compared with a similar series in which the same procedure was followed with the exception that during part of the cooling period suction and pressure were applied to the left extremity in the aluminium box. A typical observation of this kind is charted in Figure $2 B$. 
TABLE 2

Cooling of feet without suction and pressure

\begin{tabular}{|c|c|c|c|c|c|c|c|c|c|c|}
\hline \multirow{2}{*}{$\begin{array}{l}\text { Obser- } \\
\text { vation }\end{array}$} & \multirow{2}{*}{$\begin{array}{l}\text { Sub- } \\
\text { ject }\end{array}$} & \multirow{2}{*}{$\begin{array}{l}\text { Room tem- } \\
\text { perature }\end{array}$} & \multirow{2}{*}{ Digit } & \multicolumn{2}{|c|}{ Skin temperature } & \multirow{2}{*}{$\begin{array}{l}\text { Dura- } \\
\text { tion of } \\
\text { cooling } \\
\text { period }\end{array}$} & \multicolumn{2}{|c|}{$\begin{array}{l}\text { Average tem- } \\
\text { perature of air } \\
\text { in boxes }\end{array}$} & \multicolumn{2}{|c|}{$\begin{array}{l}\text { Difference } \\
\text { in skin } \\
\text { temperature }\end{array}\left\{\begin{array}{l}\text { L1-R1 } \\
\text { L3-R3 }\end{array}\right.$} \\
\hline & & & & $\begin{array}{l}\text { At be- } \\
\text { ginning of } \\
\text { cooling } \\
\text { period }\end{array}$ & $\begin{array}{l}\text { At end } \\
\text { of } \\
\text { cooling } \\
\text { period }\end{array}$ & & $\begin{array}{l}\text { Begin- } \\
\text { ning of } \\
\text { cooling } \\
\text { period }\end{array}$ & $\begin{array}{c}\text { End } \\
\text { of } \\
\text { cooling } \\
\text { period }\end{array}$ & $\begin{array}{l}\text { Begin- } \\
\text { ning of } \\
\text { cooling } \\
\text { period }\end{array}$ & $\begin{array}{l}\text { End } \\
\text { of } \\
\text { cooling } \\
\text { period }\end{array}$ \\
\hline \multirow{2}{*}{ A16 } & \multirow{2}{*}{ G. } & \multirow{2}{*}{$13.7-15.0$} & $\begin{array}{l}\text { L1 } \\
\text { L3 }\end{array}$ & $\begin{array}{l}\circ C . \\
33.6 \\
33.1\end{array}$ & $\begin{array}{l}\circ C . \\
26.8 \\
25.8\end{array}$ & \multirow{2}{*}{\begin{tabular}{|c|} 
minutes \\
40
\end{tabular}} & $\begin{array}{l}\circ C . \\
22.5\end{array}$ & $\begin{array}{l}\bullet C . \\
22.0\end{array}$ & $\begin{array}{l}\bullet C . \\
-1.1 \\
-0.5\end{array}$ & $\begin{array}{l}\circ C . \\
-1.4 \\
+0.3\end{array}$ \\
\hline & & & $\begin{array}{l}\text { R1 } \\
\text { R3 }\end{array}$ & $\begin{array}{l}34.7 \\
33.6\end{array}$ & $\begin{array}{l}28.2 \\
25.5\end{array}$ & & 23.9 & 23.1 & & \\
\hline \multirow{2}{*}{ A26 } & \multirow{2}{*}{ G. } & \multirow{2}{*}{$11.0-13.8$} & $\begin{array}{l}\text { L1 } \\
\text { L3 }\end{array}$ & $\begin{array}{l}33.4 \\
33.4\end{array}$ & $\begin{array}{l}28.6 \\
26.0\end{array}$ & \multirow{2}{*}{50} & 22.9 & 22.3 & $\begin{array}{l}-2.5 \\
-1.2\end{array}$ & $\begin{array}{r}-2.9 \\
0.0\end{array}$ \\
\hline & & & $\begin{array}{l}\text { R1 } \\
\text { R3 }\end{array}$ & $\begin{array}{l}35.9 \\
34.6\end{array}$ & $\begin{array}{l}31.5 \\
26.0\end{array}$ & & 24.5 & 23.7 & & \\
\hline \multirow{2}{*}{ A28 } & \multirow{2}{*}{ G. } & \multirow{2}{*}{$13.0-13.5$} & $\begin{array}{l}\text { L1 } \\
\text { L3 }\end{array}$ & $\begin{array}{l}34.0 \\
33.3\end{array}$ & $\begin{array}{l}25.3 \\
23.6\end{array}$ & \multirow{2}{*}{38} & 20.9 & 20.1 & $\begin{array}{l}-1.0 \\
-0.2\end{array}$ & $\begin{array}{l}-1.6 \\
-0.4\end{array}$ \\
\hline & & & $\begin{array}{l}\text { R1 } \\
\text { R3 }\end{array}$ & $\begin{array}{l}35.0 \\
33.5\end{array}$ & $\begin{array}{l}26.9 \\
24.0\end{array}$ & & 22.5 & 21.6 & & \\
\hline \multirow{2}{*}{ A29 } & \multirow{2}{*}{ L. } & \multirow{2}{*}{$14.0-15.2$} & $\begin{array}{l}\text { L1 } \\
\text { L3 }\end{array}$ & $\begin{array}{l}35.9 \\
34.6\end{array}$ & $\begin{array}{l}32.9 \\
30.5\end{array}$ & \multirow{2}{*}{50} & 23.6 & 22.4 & $\begin{array}{l}-0.2 \\
-1.2\end{array}$ & $\begin{array}{l}-1.1 \\
-2.1\end{array}$ \\
\hline & & & $\begin{array}{l}\text { R1 } \\
\text { R3 }\end{array}$ & $\begin{array}{l}36.1 \\
35.8\end{array}$ & $\begin{array}{l}34.0 \\
32.6\end{array}$ & & 25.3 & 24.0 & & \\
\hline \multirow{2}{*}{ A30 } & \multirow{2}{*}{ L. } & \multirow{2}{*}{$15.5-16.3$} & $\begin{array}{l}\text { L1 } \\
\text { L3 }\end{array}$ & $\begin{array}{l}34.7 \\
33.8\end{array}$ & $\begin{array}{l}29.3 \\
28.0\end{array}$ & \multirow{2}{*}{58} & 21.9 & 21.6 & $\begin{array}{l}-0.1 \\
-0.3\end{array}$ & $\begin{array}{l}-2.5 \\
-2.4\end{array}$ \\
\hline & & & $\begin{array}{l}\text { R1 } \\
\text { R3 }\end{array}$ & $\begin{array}{l}34.8 \\
34.1\end{array}$ & $\begin{array}{l}31.8 \\
30.4\end{array}$ & & 23.5 & 23.1 & & \\
\hline \multirow{3}{*}{ A31 } & \multirow{2}{*}{ L. } & \multirow{2}{*}{$10.7-13.0$} & $\begin{array}{l}\text { L1 } \\
\text { L3 }\end{array}$ & $\begin{array}{l}33.4 \\
33.7\end{array}$ & $\begin{array}{l}27.3 \\
26.9\end{array}$ & \multirow{2}{*}{56} & 20.5 & 19.8 & $\begin{array}{l}-0.3 \\
-0.9\end{array}$ & $\begin{array}{l}-3.8 \\
-3.6 \\
\end{array}$ \\
\hline & & & $\begin{array}{l}\text { R1 } \\
\text { R3 }\end{array}$ & $\begin{array}{l}33.7 \\
34.6\end{array}$ & $\begin{array}{l}31.1 \\
30.5\end{array}$ & & 22.1 & 21.5 & & \\
\hline & & & & & & & & erage & -0.8 & -1.8 \\
\hline
\end{tabular}

The air in the aluminium box became warmer during compression and cooler during rarefaction, as was to be expected from physical principles. The range of these fluctuations during suction and pressure has been shown in Figure $2 B$ (et seq.) by dividing the line showing air temperature in the aluminium box into two lines, of which the upper represents the 


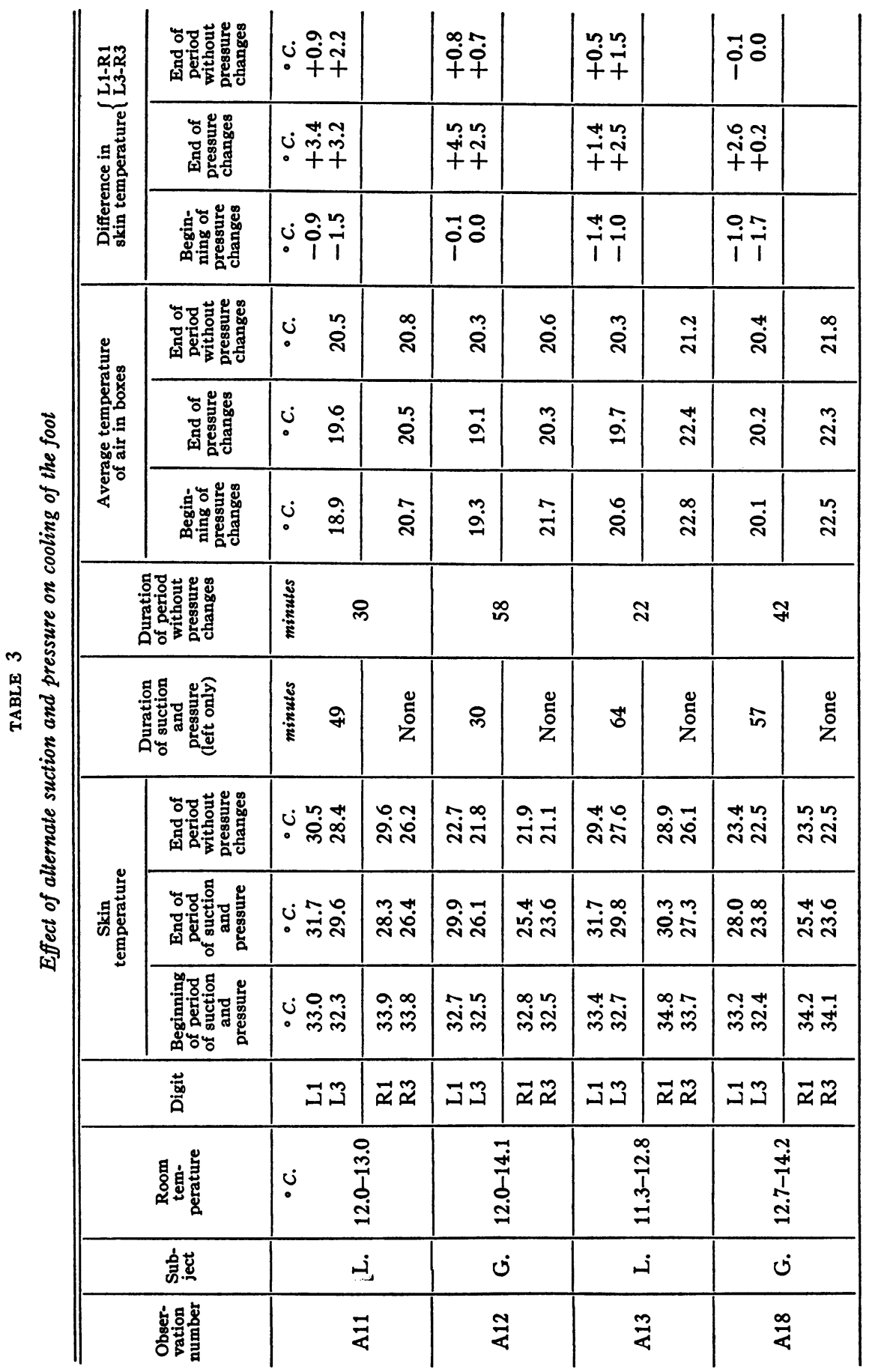


EUGENE M. LANDIS AND JOHN H. GIBBON, JR.

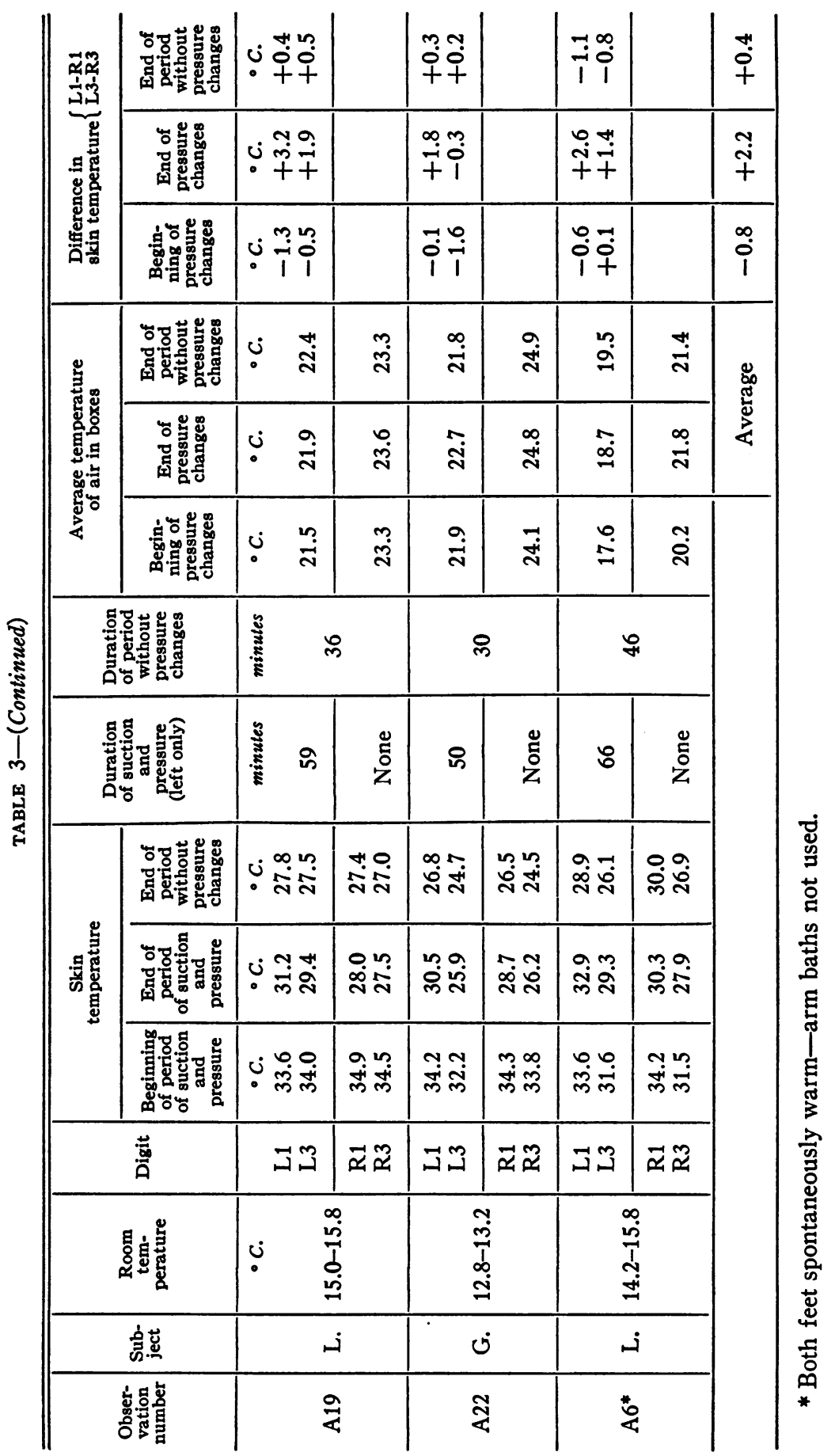


maximum temperature observed during the pressure period while the lower represents the minimum temperature observed during the period of suction. The thermal junction recording the temperature of the air in the aluminium box was connected with the galvanometer during a complete suction and pressure cycle and the highest and lowest temperatures only were recorded. The galvanometer was of the low resistance type (Leeds and Northrup, Type R) and was slightly overdamped. When relatively constant temperatures were being measured it required about 4 seconds for the galvanometer to come to rest. Positive pressure was applied for 5 seconds, a period slightly longer than that required for the galvanometer to reach equilibrium. The fluctuations in air temperature proved to be relatively uniform as shown in Figures $2 B, 4 A$, etc.

The air in the aluminium box was at the higher temperature for less than $1 / 3$ of the time while the lower temperature prevailed for over $2 / 3$ of the time. The average temperature of the air in the aluminium box would therefore be represented by a line slightly lower than midway between the maximum and minimum temperatures shown. Nevertheless, the air in the control box was kept warmer than the highest temperature recorded in the aluminium box since the effects of suction and pressure were being measured in terms of the cooling of the left, as compared to the right, extremity.

Under these conditions, suction and pressure modified the skin temperature of the left extremity as shown in Figure $2 B$. The right digits cooled uniformly and evenly during the entire period. The left digits, however, cooled more slowly during the application of suction and pressure. In the observation illustrated in Figure $2 B$ during the early part of the suction and pressure period the left first digit was approximately $2^{\circ}$ cooler than the right first digit. At the end of the suction and pressure period, 57 minutes later, the left first digit was approximately $3^{\circ}$ warmer than the right. When suction and pressure were discontinued the left extremity began to cool much more rapidly and finally reached the same temperature as the right.

Six such observations, and one in which warming occurred spontaneously, are summarized in Table 3. Room temperature ranged from 11.3 to $15.8^{\circ} \mathrm{C}$. At the beginning of the cooling period the surface temperatures of the digits were all above $31^{\circ} \mathrm{C}$., the left digits being with one trifling exception cooler than the right. The right extremity was allowed to cool in the control box, while the left extremity was exposed to alternate suction and pressure for periods of 30 to 66 minutes. Suction and pressure were then stopped and the temperatures of both extremities were observed for 22 to 58 minutes more.

The average temperature of the air in the control box was computed as described for Table 2. In computing the temperatures of the air in the aluminium box, however, it was necessary to average the first five maxi- 
mum and the first five minimum readings. This figure is probably higher than true mean air temperature for reasons mentioned above. The air in the control box was kept approximately $2^{\circ} \mathrm{C}$. higher than this computed average and slightly higher than the maximum temperature in the aluminium box.

The relation between the surface temperatures of the right and left digits is summarized in the last three columns of Table 3 . The temperature of the right first digit has been subtracted from that of the left first digit $(a)$ at the beginning of pressure changes, $(b)$ at the end of pressure changes, and $(c)$ at the end of the period without pressure changes. The third toes have been similarly compared as regards temperature.

As in Table 2 a minus sign indicates that the left digit was cooler by the amount given while a plus sign indicates that the left digit was warmer. At the beginning of suction and pressure the left digits were, with one exception, from 0 to $1.7^{\circ} \mathrm{C}$. cooler than the right digits. At the end of the suction and pressure periods the left digits were, with one exception, from 0.2 to $4.5^{\circ} \mathrm{C}$. warmer than the right. In the two exceptions noted the left digit cooled much less rapidly than the right, though the difference was not enough to change the sign. During the subsequent period when cooling continued without the application of suction and pressure to the left extremity, the difference between the temperatures of the two extremities diminished conspicuously. In some instances the left extremity became once more the cooler; in every instance the difference in temperature became distinctly less.

The results are summarized in the average figures recorded in the lower right hand corner of Table 3. At the beginning of suction and pressure the left digits averaged $0.8^{\circ} \mathrm{C}$. cooler. than the right. At the end of the suction and pressure period the left digits averaged $2.2^{\circ} \mathrm{C}$. warmer than the right. After a period without suction and pressure this difference diminished conspicuously, finally amounting to only $0.4^{\circ} \mathrm{C}$. This forms a marked contrast to the control observations recorded in Table 2 , in which without suction and pressure the left digits, instead of becoming warmer, cooled slightly more rapidly than the right or control digits. The difference in the rate of cooling must be ascribed to the relatively greater flow of arterial blood into the skin of the extremity exposed to suction and pressure.

2. The influence of suction and pressure on blood flow in the cool extremities of normal subjects.

The effects on skin temperature of applying suction and pressure to the cool extremity were observed in order to ascertain whether blood flow could be increased in the presence of more or less marked vasoconstrictor tone. Room temperature was low, varying from 8.9 to $19.9^{\circ} \mathrm{C}$. The subjects in these observations were usually cool or cold to the point of shivering. As was to be expected under these conditions skin temperatures 
tended to approach environmental temperature during the period preceding the application of suction and pressure.

The left extremity was placed in the aluminium box, the right extremity being used as a control. The air in the control box was kept warmer than that in the aluminium box throughout the observation. The effects of applying alternate suction and pressure to the cool extremity varied considerably. Figures $3 A$ and $3 B$ represent the type of change observed in 6 of
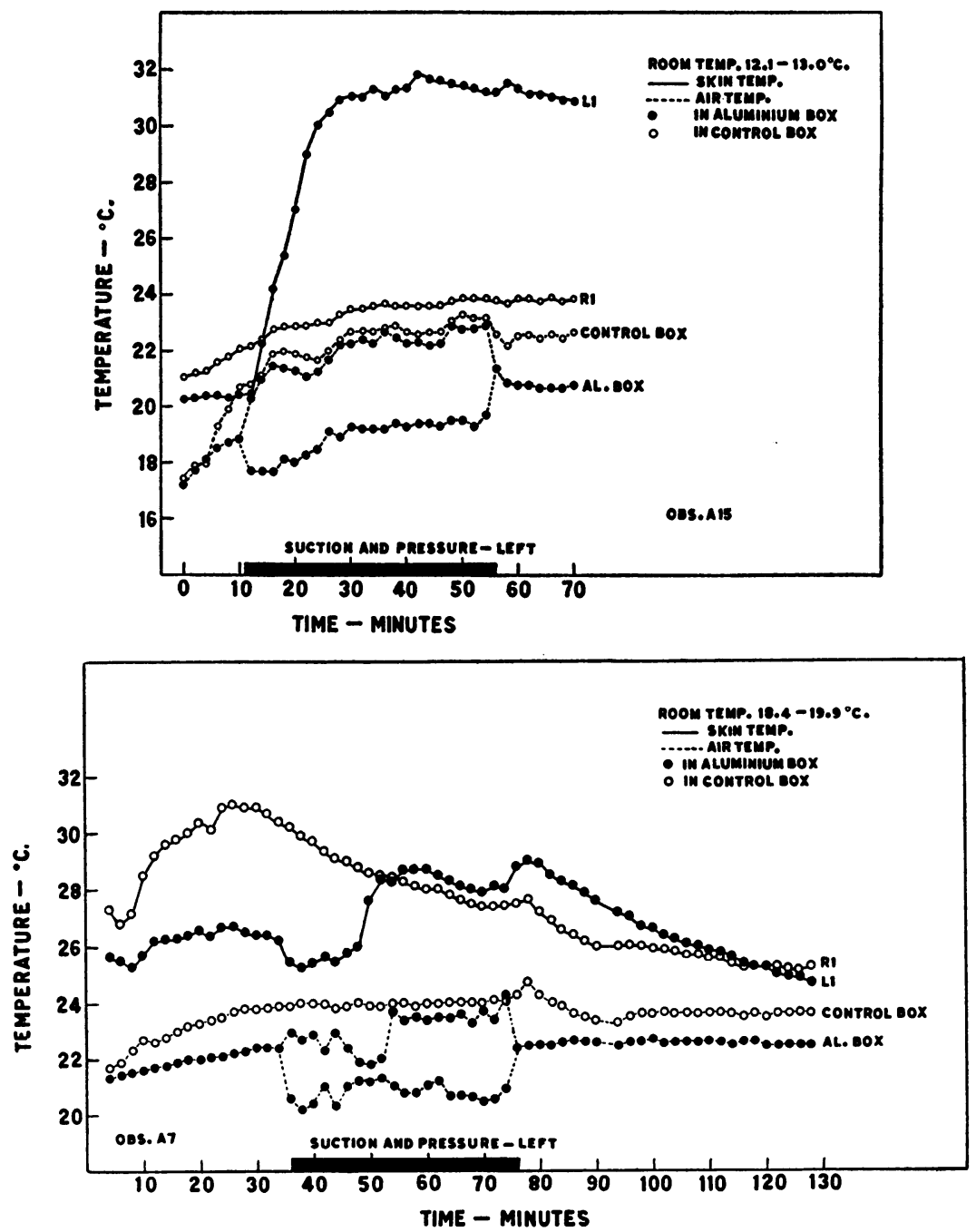

Figs. $3 A$ and $3 B$. Showing the Effects of Suction and Pressure on the Temperature of the Previously Cool Lower Extremity

The left extremity was in the aluminium box and was exposed to pressure changes. The right extremity was in the control box. 
10 observations. With the beginning of suction and pressure the skin temperature of the left digits began to rise more or less rapidly, while the right digits either cooled or showed no rise in temperature other than might have been expected from the gradual warming of the control box.

As shown in the upper part of Table 4 suction and pressure increased blood flow in the cold extremity in 6 of 10 observations on two normal subjects. The left digits warmed by as much as $11.3^{\circ} \mathrm{C}$. while the right digits either cooled, or warmed by not more than $2.2^{\circ} \mathrm{C}$. Expressed for convenience in the form of average figures the results may be summarized by stating that in these 6 observations the left digits, exposed to suction and pressure, became warmer by $6.3^{\circ} \mathrm{C}$. while the right digits, though exposed to a higher air temperature, became warmer by only $0.3^{\circ} \mathrm{C}$.

The lower section of Table 4 and the first portion of Figures $4 A$ and $4 B$ summarize the observations in which suction and pressure alone did not influence blood flow conspicuously. The data in Table 4 apply only to the period when suction and pressure were used without immersion of the forearms in warm water, the latter being considered in the next section. These four observations may be summarized by stating that the left digits exposed to suction and pressure (before diminishing vasoconstrictor tone by immersing one forearm in warm water) showed, on the average, no change in temperature while the right digits became cooler by $1^{\circ} \mathrm{C}$. though the latter were exposed to a warmer air temperature. This difference is doubtless too small to be of any real significance, though in qualitative agreement with the other observations in which larger changes were observed. High vasoconstrictor tone can apparently diminish the effects which suction and pressure exert on blood flow.

It was mentioned previously that theoretically the effects of suction and pressure would be expected to depend upon the presence of an adequate reservoir to accommodate the blood drawn through the arterioles during the suction period. It has been shown by Lewis (5) that during vasoconstriction the minute vessels of the skin can resist internal positive (or external negative) pressures of 50 to $100 \mathrm{~mm}$. Hg. The negative pressure applied to the surface of the skin was $-120 \mathrm{~mm}$. Hg. It is very doubtful whether this pressure is transmitted without loss through the surface of the skin. It is quite likely that during vasoconstriction the effective negative pressure which reaches the walls of the blood vessels could be easily withstood by vessels capable of resisting internal pressures of 50 to 100 $\mathrm{mm}$. Hg. Under these circumstances, therefore, in the absence of an adequate reservoir for the accommodation of blood flowing through the arterioles it would be expected that with high vasoconstrictor tone the effectiveness of suction and pressure would be diminished if not completely absent in some instances. The effect of immersing one forearm in warm water (Figs. $4 A$ and $4 B$ ) is in favor of this explanation. As soon as vasoconstrictor tone was reduced slightly a reservoir became available and 


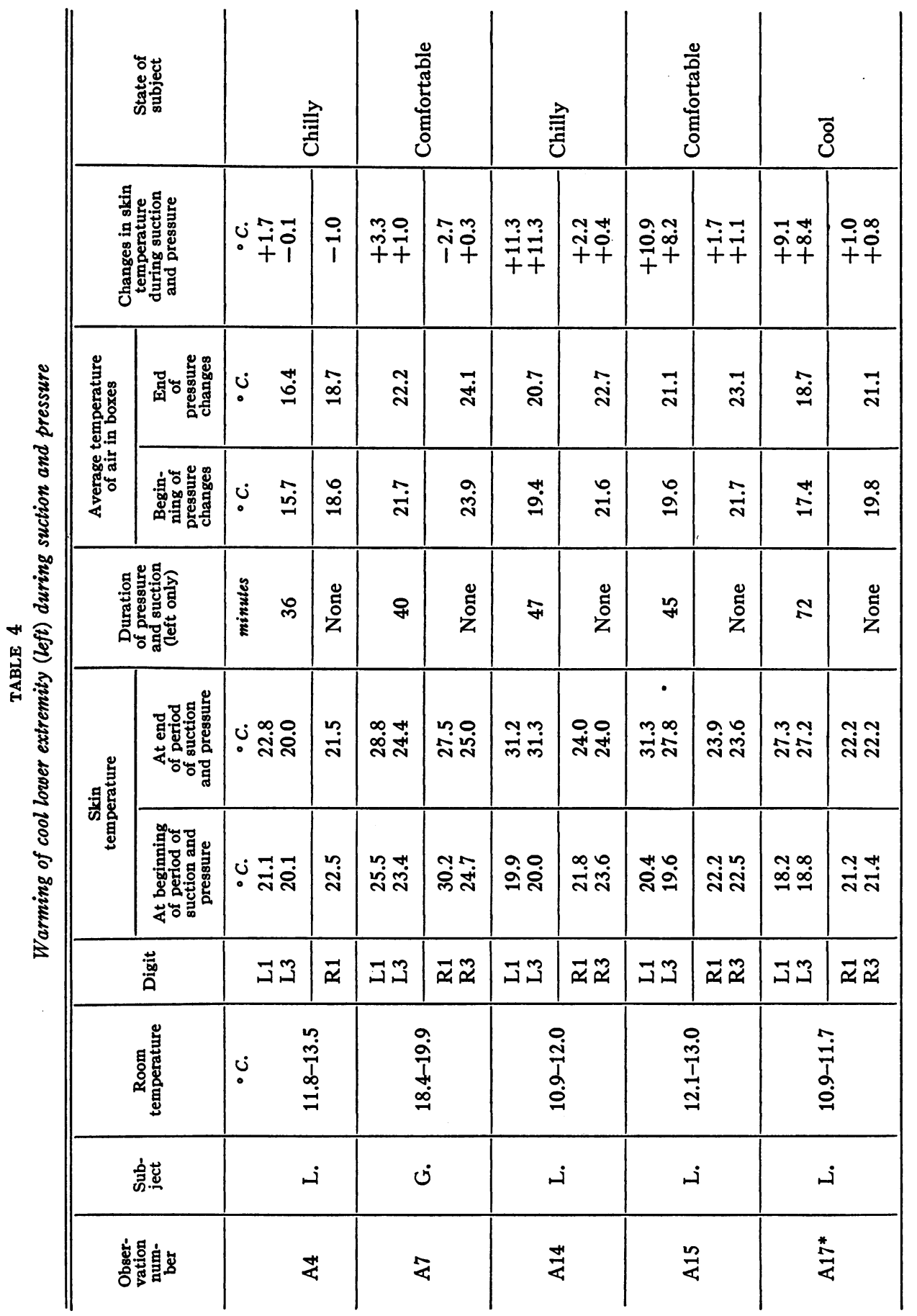


EUGENE M. LANDIS AND JOHN H. GIBBON, JR.

\begin{tabular}{|c|c|c|c|c|c|c|c|c|c|c|c|c|}
\hline \multicolumn{2}{|c|}{ 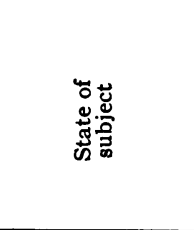 } & \multicolumn{2}{|c|}{ 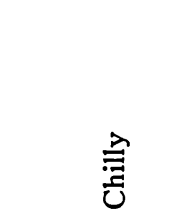 } & & & \multicolumn{2}{|c|}{ 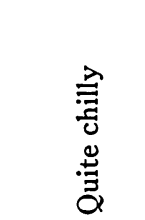 } & \multicolumn{2}{|c|}{$\overline{8}$} & \multicolumn{2}{|c|}{ 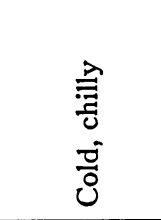 } & \multirow{11}{*}{ 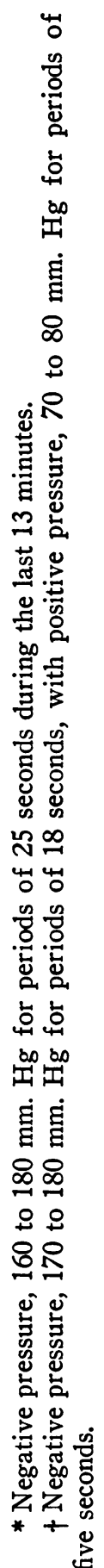 } \\
\hline \multicolumn{2}{|c|}{ 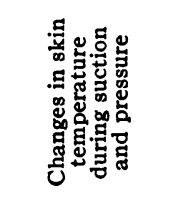 } & ن & $\stackrel{\infty}{i} \stackrel{0}{i}$ & $\begin{array}{l}90 \\
\dot{0}\end{array}$ & $\stackrel{-1}{+}$ & 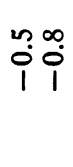 & $\stackrel{\infty}{+}$ & $\begin{array}{l}0+0 \\
\dot{0}\end{array}$ & $\ddot{q}_{i}^{0}$ & $\dddot{0}_{i}^{\infty} \dot{0}_{1}^{\circ}$ & T: & \\
\hline \multirow{2}{*}{ 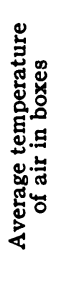 } & 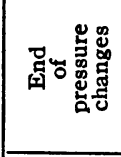 & ن & $\vec{d}$ & ֻัं & $\stackrel{m}{i}$ & $\stackrel{\vec{n}}{\rightarrow}$ & $\stackrel{m}{0}$ & 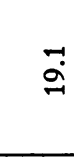 & m̊. & $\vec{a}$ & $\stackrel{n}{\text { ก }}$ & \\
\hline & 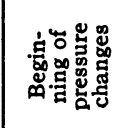 & ن & $\vec{d}$ & $\begin{array}{l}\infty \\
\stackrel{\circ}{\sigma}\end{array}$ & $\stackrel{n}{\text { n }}$ & นึ. & m & $\stackrel{1}{=}$ & ڤें & $\stackrel{m}{a}$ & 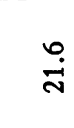 & \\
\hline \multicolumn{2}{|c|}{ 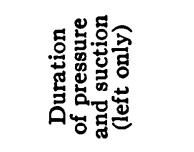 } & 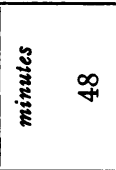 & : & in & 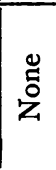 & oे & 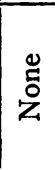 & Ḧ & 芩 & 아 & $\begin{array}{l}\text { : } \\
\text { z }\end{array}$ & \\
\hline \multirow{2}{*}{ 鸪总 } & 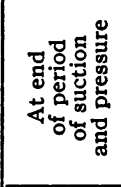 & ن & 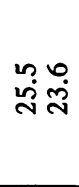 & ণั & กุ & $\begin{array}{l}n \\
\infty \\
\infty \\
\infty\end{array}$ & 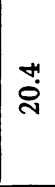 & ப் & ֻ̊ & $\begin{array}{l}0 \\
\infty \\
\infty \\
\rightarrow\end{array}$ & $\tilde{\tilde{N}}$ & \\
\hline & 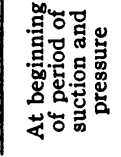 & ن & 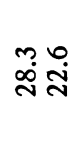 & $\ddot{\sim} \dot{\alpha}$ & $\stackrel{+}{i}$ & $\begin{array}{l}0 \infty \\
\stackrel{\infty}{\infty}\end{array}$ & นี่ & 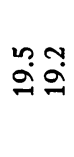 & o̊ & $\ddot{9} 2$ & חొ & \\
\hline & 莒 & $\exists 3$ & $\vec{\approx} \tilde{\simeq}$ & تే゙ & $\vec{\sim}$ & تేష & $\vec{a}$ & コ㕦 & $\overrightarrow{\not x}$ & تే & $\vec{z} \approx$ & \\
\hline & 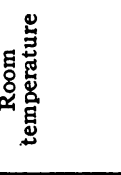 & \multicolumn{2}{|c|}{$\begin{array}{l}0 \\
\stackrel{0}{0} \\
\vec{b} \\
\dot{0}\end{array}$} & \multicolumn{2}{|c|}{ 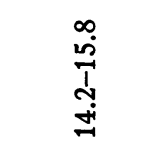 } & \multicolumn{2}{|c|}{ 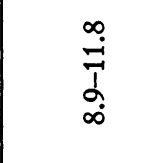 } & \multicolumn{2}{|c|}{$\begin{array}{l}\stackrel{m}{0} \\
\stackrel{0}{b} \\
\ddot{m}\end{array}$} & \multicolumn{2}{|c|}{ 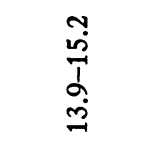 } & \\
\hline & 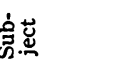 & \multicolumn{2}{|c|}{$\dot{0}$} & \multicolumn{2}{|c|}{ ن } & \multicolumn{2}{|c|}{ ـ } & \multicolumn{2}{|c|}{ ن } & & & \\
\hline \multicolumn{2}{|c|}{ 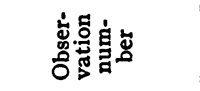 } & \multicolumn{2}{|c|}{ 志 } & \multicolumn{2}{|c|}{$\varangle$} & \multicolumn{2}{|c|}{$<$} & & 4 & & & \\
\hline
\end{tabular}



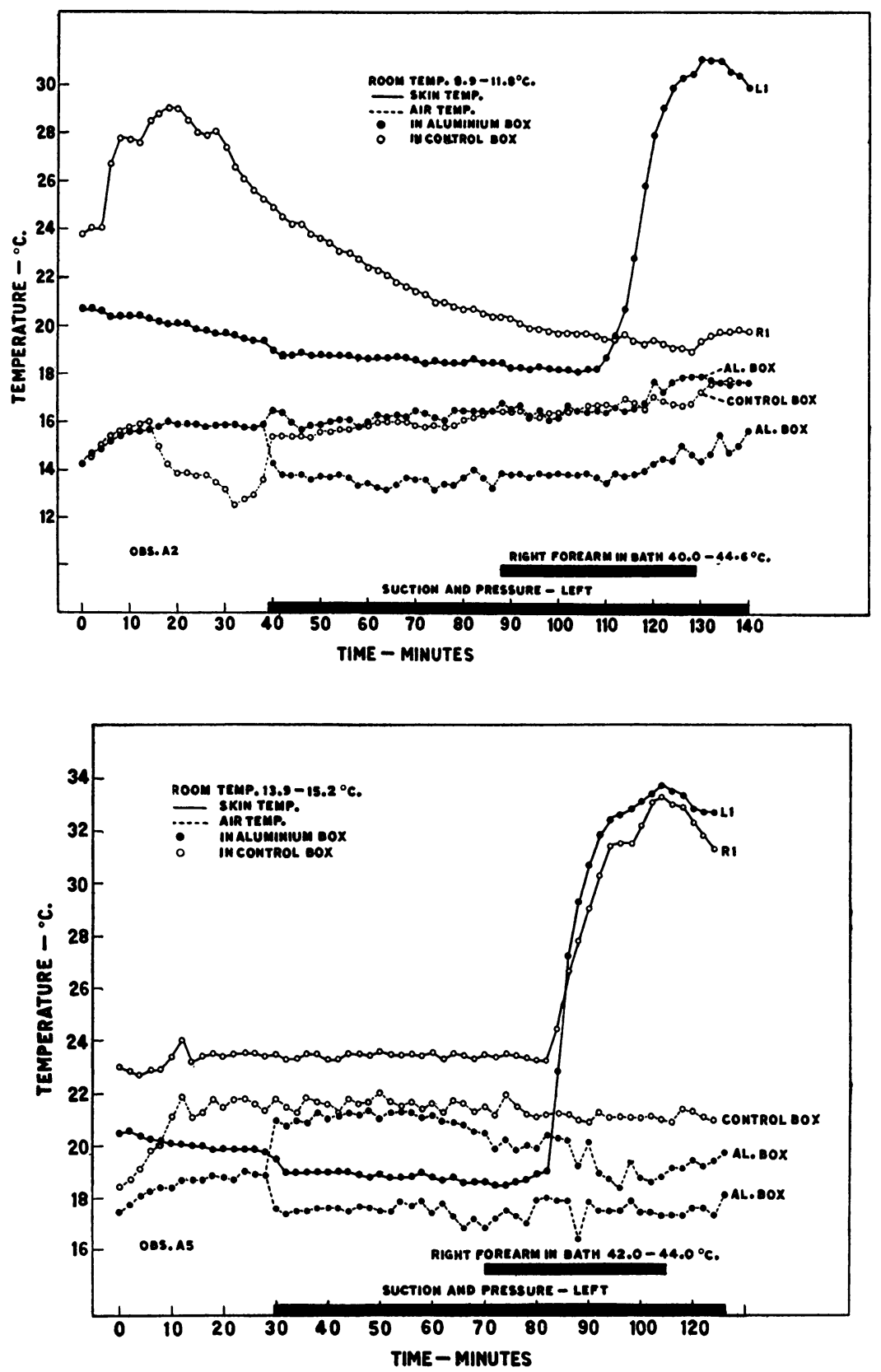

Figs. $4 A$ and $4 B$. Showing (1) Absence of Change in Skin Temperature during Simpie Suction and Pressure and (2) Marked Rise in Skin Temperature during Suction and Pressure (Left Extremity) Accompanying the Immersion of One Forearm in Warm Water. 
suction and pressure favored blood flow through the left extremity, as shown by the greater rise in skin temperature. The results suggest that the maximal effects of alternate suction and pressure can be obtained only if vasoconstrictor tone is not too great.

3. The effects of suction and pressure on the vasodilator response to immersing one forearm in warm water.

Gibbon and Landis (3) showed that immersing one or two forearms in warm water produced vasodilatation, more or less complete in grade, in the lower extremities. In agreement with Lewis and Pickering (4) it was observed that in general the vasodilator response began first in the warmer extremity and that the final temperature reached at the end of 35 minutes was slightly higher in the extremity originally the warmer.

The effects of suction and pressure on the vasodilator response were studied, in order to determine whether blood flow was modified by external pressure changes. Control observations were made in which the vasodilator. response was induced in the lower extremities without the use of suction and pressure (Fig. 5). The left extremity was placed in the aluminium box, the right in the control box; the air temperature in the latter was kept uniformly higher than that in the aluminium box. In all observations the right or control extremity was slightly warmer at the time the forearm was immersed in the warm bath. The forearm remained in the bath for 35 minutes.

In Table $5 A$ six such control observations are summarized. The average temperature of the air in the boxes was computed as in the previous tables. In the third column from the right the temperature of a digit was regarded as having begun to rise when it was $1^{\circ} \mathrm{C}$. above the temperature existing when the forearms were immersed. In agreement with previous observations the right, or warmer, digits, with one exception, showed the vasodilator response sooner than the corresponding left, or cooler, digits. In the last two columns of Table $5 \mathrm{~A}$ the temperatures of the corresponding digits are compared as in previous tables. At the time the forearm was immersed in warm water, the left digits were the cooler by 0.4 to $1.7^{\circ} \mathrm{C}$., with an average difference of $1.1^{\circ} \mathrm{C}$. At the end of the 35 minute immersion period the same relationship (with one exception) existed, the left digits remaining the cooler throughout with an average difference (including the one exception) of $1.8^{\circ} \mathrm{C}$. This agrees with previous findings and serves as a control for those observations in which suction and pressure were used in combination with warming of one forearm for 35 minutes.

Figures $4 A$ and $B$ show that suction and pressure favored the development of the vasodilator response in the lower extremity exposed to pressure variations. In one observation (Fig. $4 A$ ) the warmer control extremity showed no vasodilator response whatever when the right forearm was immersed in warm water while the left extremity exposed to suction and 


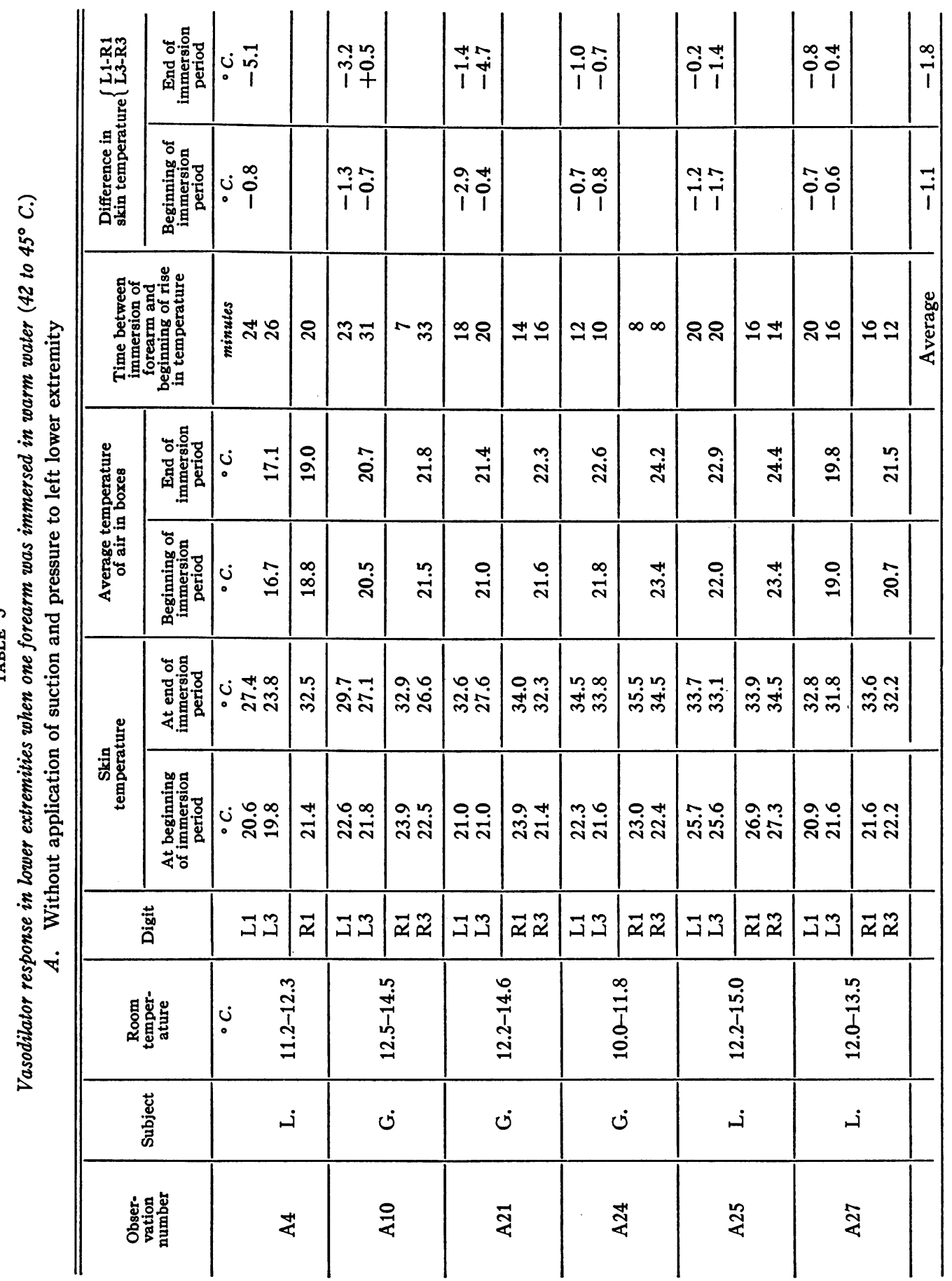


EUGENE M. LANDIS AND JOHN H. GIBBON, JR.

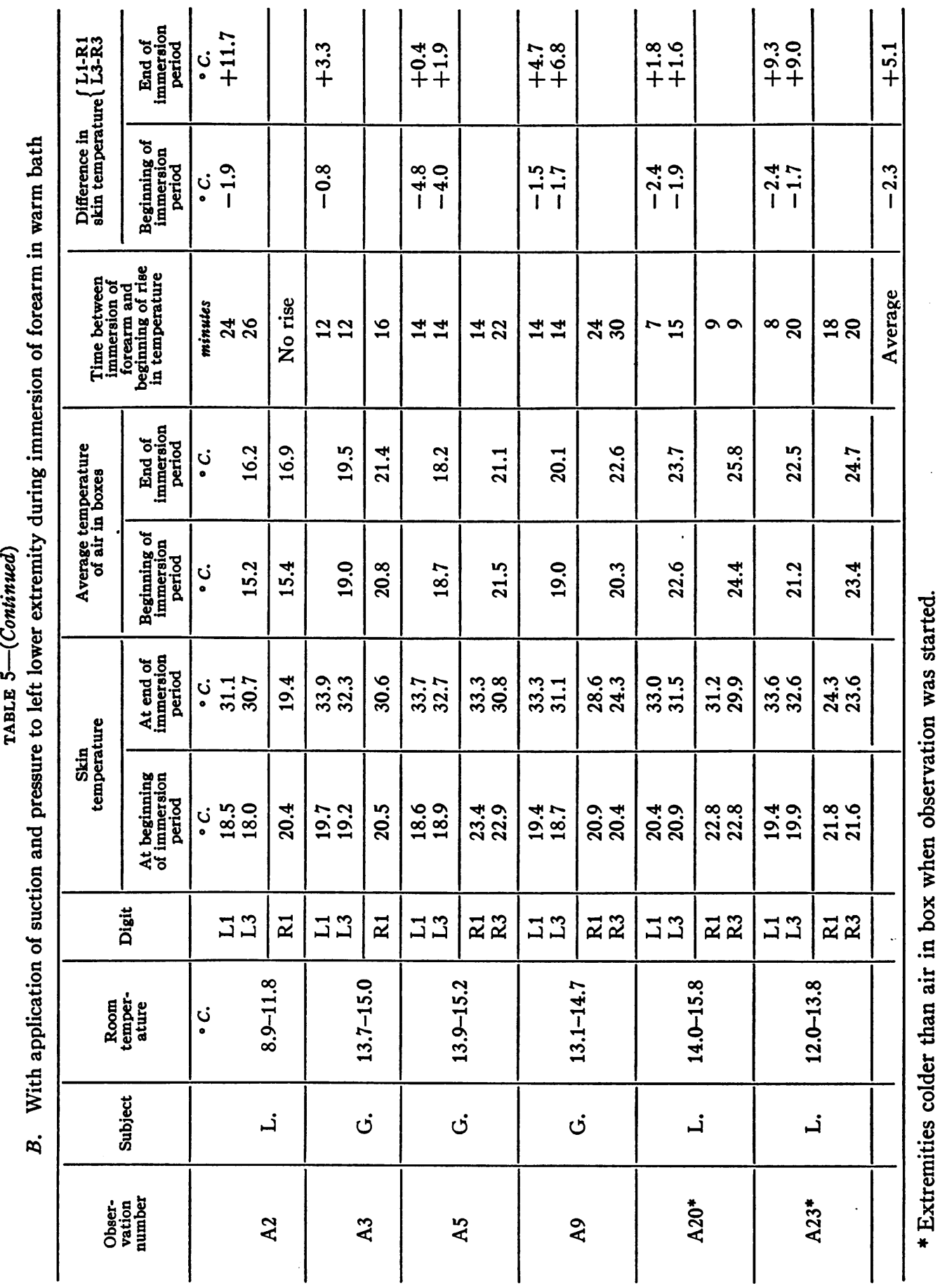


pressure showed an almost complete response. In Figure $4 B$ the right extremity though at a higher temperature originally warmed more slowly and less completely than did the cooler left extremity, the latter being exposed to suction and pressure.

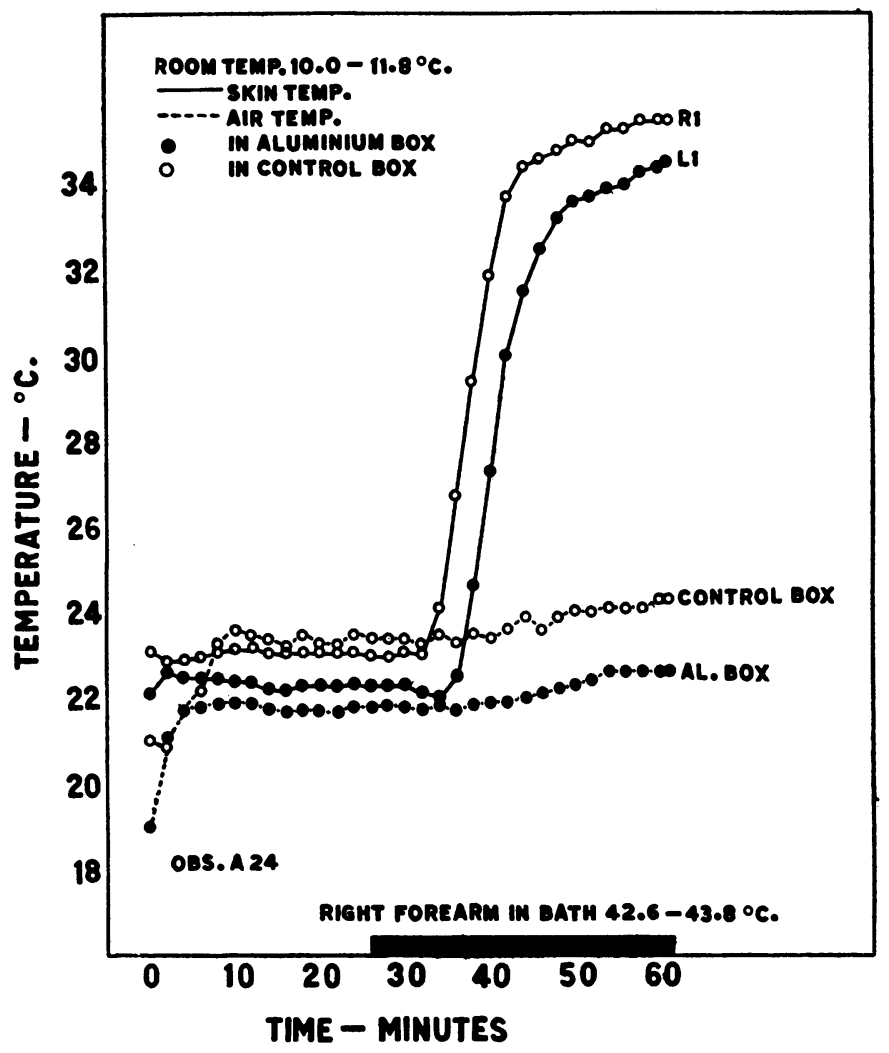

Fig. 5. Control Observation Showing Vasodilator Response Induced in the LoWer Extremities by Immersing One Forearm in Warm Water Suction and pressure were not applied.

Table $5 B$ summarizes six such observations. At the beginning of the immersion period the left digits were cooler than the right digits by amounts varying between 0.8 and $4.8^{\circ} \mathrm{C}$. Nevertheless, when one forearm was immersed in warm water while suction and pressure were applied to the left lower extremity the left digits warmed until they were from 0.4 to $11.7^{\circ}$ warmer than the right. This occurred even though the air in the control box was approximately $1.5^{\circ} \mathrm{C}$. warmer than that in the aluminium box. In addition the vasodilator response tended to appear first in the left extremity which at the time the forearm was immersed was usually about $2^{\circ} \mathrm{C}$. cooler. 
The difference between the control and experimental observations can be summarized in the form of averages. Without suction and pressure the left extremity, originally cooler, began to show a vasodilator response 20 minutes after the forearm was immersed while the right, being warmer, began to show the vasodilator response in 15 minutes. The left extremity, originally $1.1^{\circ} \mathrm{C}$. cooler than the right, remained cooler by $1.8^{\circ} \mathrm{C}$. even at the height of vasodilatation. On the contrary, when suction and pressure were applied to the left lower extremity the vasodilator response appeared first in the cooler (left) extremity 15 minutes after the forearm was immersed, and in the warmer (right) extremity 20 minutes after the forearm was immersed in warm water. Moreover, while the left lower extremity was cooler than the right by $2.3^{\circ} \mathrm{C}$. at the beginning of the immersion period it became warmer than the right by $5.1^{\circ} \mathrm{C}$. at the end of the immersion period when suction and pressure were used. Suction and pressure therefore reversed the findings observed in control experimentsfurther evidence that negative pressure favors increased blood flow. The control observations rule out the possibility that the differences were due to chance variations in the reactions of the two extremities.

\section{The effects of alternate suction and pressure on skin temperature in patients with peripheral vascular disease}

Five patients with varying grades of peripheral vascular disease were studied. In each patient alternate suction and pressure produced a conspicuous rise of surface temperature in the affected extremity, even in the presence of advanced organic vascular disease. In these observations the room temperature was kept between 14.0 and $19.5^{\circ} \mathrm{C}$. - cool enough to keep air temperature within the boxes moderately low but not so cold as to be uncomfortable. The patients were in the semi-recumbent position on a couch with a back rest. One lower extremity was placed in the aluminium box while the other was placed in the control box. As usual, the air in the latter box was kept slightly warmer than the air in the aluminium box. The patients experienced no discomfort during the procedure, even falling asleep in one instance while suction and pressure were applied. Skin and air temperatures were measured in the manner described for normal subjects.

Patient 1, a white male, aged 61 , was known to have suffered from diabetes mellitus since the age of 56 . His blood sugar was well controlled by diet alone. For approximately two years the patient had noticed numbness, extreme coldness, and moderate cyanosis of both feet without intermittent claudication, or ulceration. Examination revealed generalized arteriosclerosis with a blood pressure of $155 \mathrm{~mm}$. $\mathrm{Hg}$ systolic and $85 \mathrm{~mm} . \mathrm{Hg}$ diastolic. On numerous occasions both lower extremities were found to be cold and slightly to moderately cyanotic in color. The skin of the right lower extremity from the middle of the leg downward was thickened and scaly and all the toe nails were abnormally ridged and thickened. Neither 
the posterior tibial nor the dorsalis pedis pulse could be felt on the right. The left posterior tibial artery pulsated normally but the left dorsalis pedis could not be felt.

On two occasions immersing both forearms in warm water failed to produce a vasodilator response in either. lower extremity. Moreover, anesthetization by novocaine of both posterior tibial nerves failed to produce any rise in skin temperature. Figure $6 \mathrm{~A}$ shows the skin temperatures of the right and left first toes $(a)$ during immersion of both forearms in warm water $\left(42.8-45.1^{\circ} \mathrm{C}\right.$.) for 35 minutes and $(b)$ during anesthetization of the right posterior tibial nerve. The skin temperature, approximately $22^{\circ} \mathrm{C}$. at the beginning, did not rise during either of these procedures, both of which remove vasoconstrictor tone, and, in normal subjects, produce vasodilatation with a rise of skin temperature to $30.5^{\circ} \mathrm{C}$. or more. Anesthetization of the left posterior tibial nerve also failed to produce any evidence of vasodilatation in the left foot. This patient, therefore, had organic arterial obstruction advanced to such a stage that obliteration of vasoconstrictor tone by two different methods could not increase local blood flow significantly. In numerous examinations the skin temperatures in both feet were never more than slightly above room temperature.

The effects of alternate suction and pressure combined with reduction of vasoconstrictor tone are shown in Figure $6 B$. The left lower extremity was placed in the control box, the right lower extremity in the aluminium box. After the temperatures had become relatively constant the right forearm was immersed in warm water $\left(42.0\right.$ to $44.1^{\circ} \mathrm{C}$.). This failed to increase blood flow-in agreement with the previously described complete absence of the vasodilator response. Suction and pressure were applied to the right lower extremity and the surface temperature of the right first toe began to rise within a few minutes, finally exceeding $30^{\circ} \mathrm{C}$., while the temperature of the left first toe, in the warmer control box, remained below $24^{\circ} \mathrm{C}$., showing only a tendency slowly to approach the environmental temperature. During the periods of negative pressure the skin of the right foot was definitely pink, blanching during the period of positive pressure. At the end of the observation the patient remarked spontaneously that the right foot was distinctly warmer to touch than the left.

On another occasion conditions were reversed. As shown in Figure $6 C$, the warmer right extremity was placed in the control box, the cooler left extremity in the aluminium box. Suction and pressure were applied to the left extremity for 38 minutes without conspicuous change in the temperature of the left first digit. One forearm was then immersed in warm water. The temperature of the right first digit rose very slowly, remaining only slightly above that of the air within the control box. The left first digit, originally cooler, finally became $4^{\circ} \mathrm{C}$. warmer than the right first digit and its temperature was conspicuously higher than that of the surrounding air. The third digits showed similar changes. 


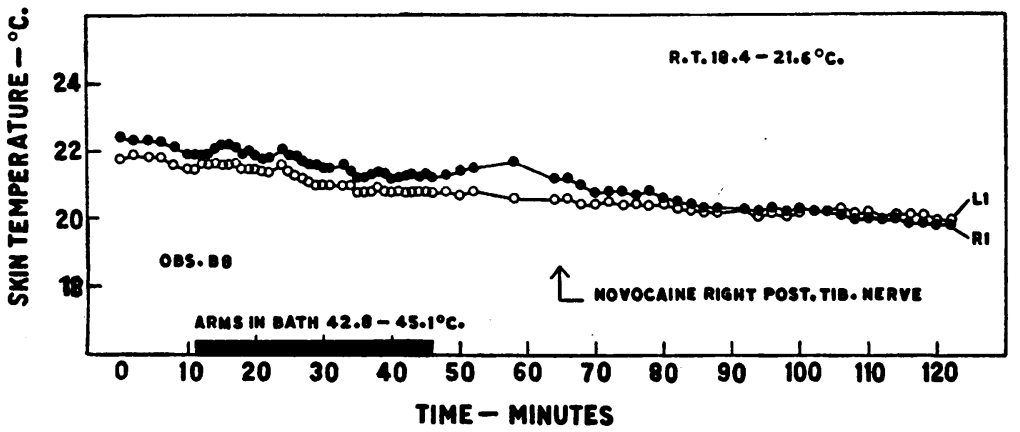

Fig. 6A. Showing Complete Absence of Vasodilator Response in Patient 1 DURing (1) ImMersion of ARMS IN Warm Water, and (2) DURING Anesthetization of the Right Posterior Tibial Nerve.

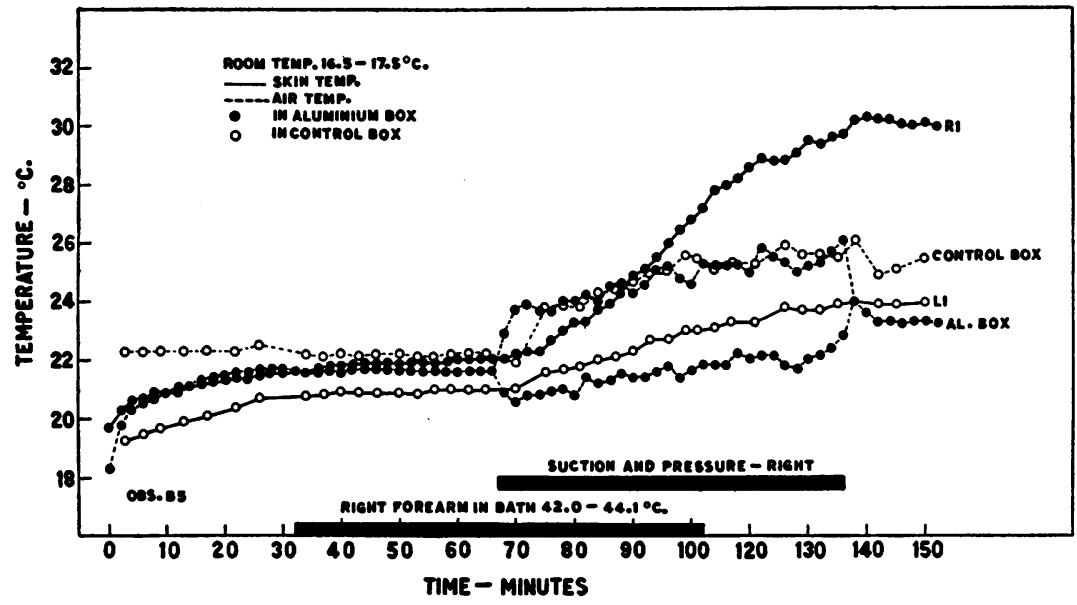

Fig. 6B. Showing Rise in Skin Temperature of the Right Lower Extremity during Application of Suction and Pressure

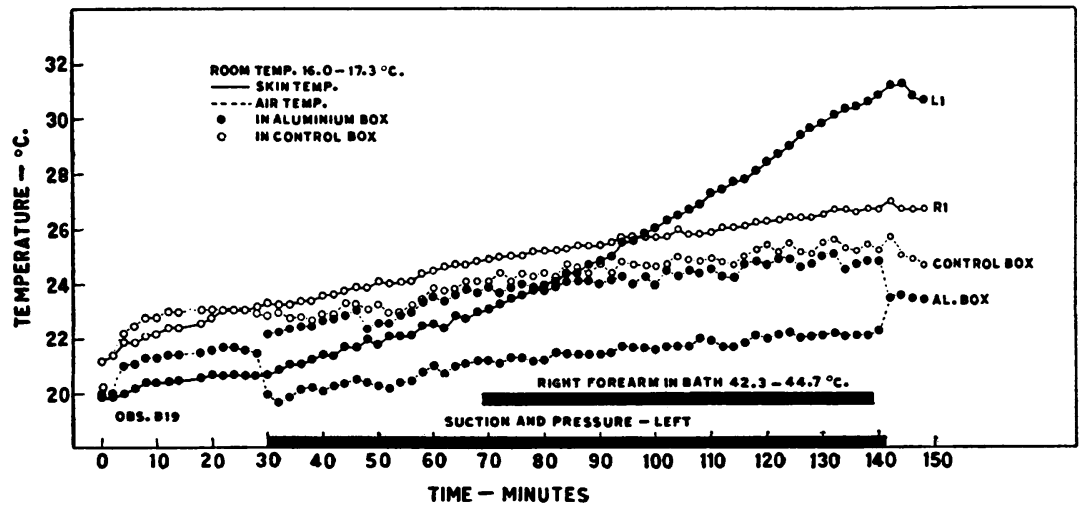

Fig. 6C. Showing Rise in Skin Temperature of Left Lower Extremity during Application of Suction and Pressure 


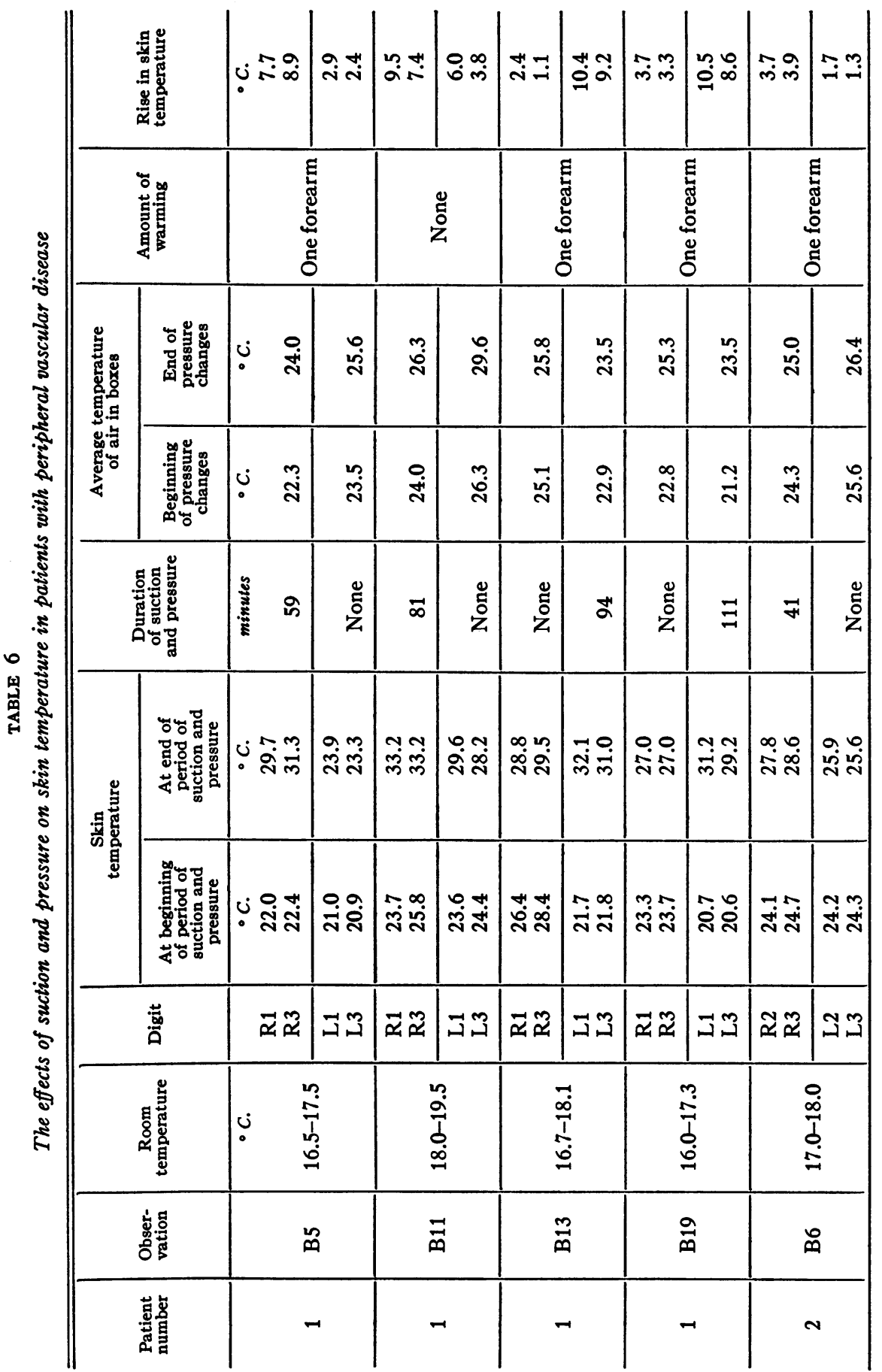


EUGENE M. LANDIS AND JOHN H. GIBBON, JR.

\begin{tabular}{|c|c|c|c|c|c|c|c|c|c|c|c|c|c|}
\hline & 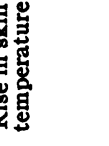 & ن & $\stackrel{\infty}{i} \vec{i}$ & 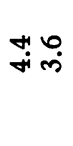 & $\begin{array}{ll}0 & * \\
0 & 0 \\
i & 1\end{array}$ & ڤִ & $\stackrel{\circ}{\circ} \underset{+}{0}$ & $\left(\begin{array}{ll}\infty & 0 \\
\sim & \sim\end{array}\right.$ & $\begin{array}{ll}0 & 0 \\
& 0 \\
1 & 0\end{array}$ & $\vec{i} \stackrel{m}{-}$ & ڤ̊ & 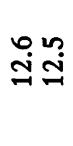 & $\vec{m}$ \\
\hline \multicolumn{2}{|c|}{ 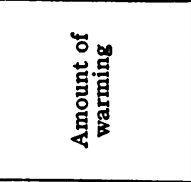 } & \multicolumn{2}{|c|}{$\begin{array}{l}\text { Z̆ } \\
\text { z }\end{array}$} & \multicolumn{2}{|c|}{ 芩 } & \multicolumn{2}{|c|}{ 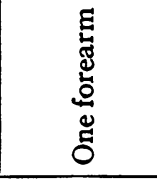 } & \multicolumn{2}{|c|}{ 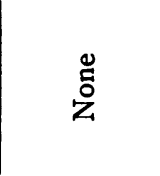 } & \multicolumn{2}{|c|}{ 芩 } & \multicolumn{2}{|c|}{ 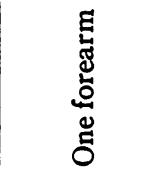 } \\
\hline \multirow{2}{*}{ 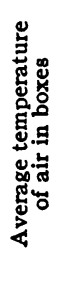 } & 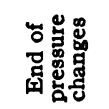 & 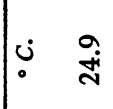 & $\stackrel{\circ}{\stackrel{1}{N}}$ & 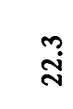 & $\stackrel{\circ}{\stackrel{\sim}{+}}$ & 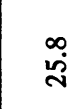 & 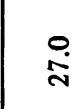 & : & $\stackrel{n}{\stackrel{n}{*}}$ & $\vec{i}$ & $\stackrel{m}{\sim}$ & $\stackrel{a}{i}$ & $\stackrel{3}{\text { i }}$ \\
\hline & 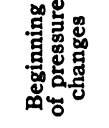 & $\begin{array}{ll}ن & \stackrel{a}{\text { N }}\end{array}$ & ஷே & $\stackrel{0}{\text { ì }}$ & 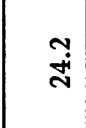 & $\ddot{n}$ & $\begin{array}{l}\stackrel{+}{\text { d }} \\
\text { }\end{array}$ & $\overrightarrow{\text { Dे }}$ & $\begin{array}{l}\dot{0} \\
\dot{0}\end{array}$ & 㐫 & 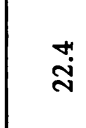 & ¿̊. & $\stackrel{+}{\text { N }}$ \\
\hline \multicolumn{2}{|c|}{ 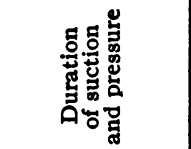 } & 苋 & 气̆ & 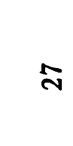 & $\begin{array}{l}\text { ¿ } \\
\text { z }\end{array}$ & $\stackrel{\infty}{=}$ & : & in & $\begin{array}{l}\stackrel{\Xi}{0} \\
\text { Z }\end{array}$ & $\overrightarrow{\text { in }}$ & $\stackrel{\text { ğ }}{z}$ & $\bar{\infty}$ & こّ̊ \\
\hline \multirow{2}{*}{ 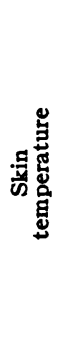 } & 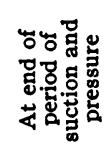 & ن & 足 & n̊요 & 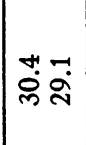 & 孞 & 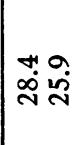 & ホัँ & $\begin{array}{l}0 \\
\text { ลें }\end{array}$ & 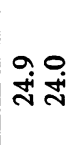 & तั & तెं & गें \\
\hline & 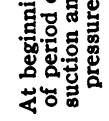 & ن 完 & ㄱ. & 芒苍 & "ே & 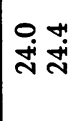 & tia & $\begin{array}{l}0 \\
\text { 워 }\end{array}$ & Nִ & ָี ิี & $\begin{array}{l}00 \\
\text { הై }\end{array}$ & ڤ̊ำ & $\begin{array}{l}900 \\
\dot{\sigma}\end{array}$ \\
\hline \multicolumn{2}{|r|}{$\begin{array}{l}\stackrel{0}{*} \\
\vec{A}\end{array}$} & $\vec{\alpha} \ddot{\sim}$ & 포 & $\vec{\sim} \tilde{\sim}$ & ゴ & $\bar{x} \tilde{x}$ & ב3 & $\vec{\alpha} \tilde{\sim}$ & ヨコ & $\vec{\alpha} \tilde{\sim}$ & ニ゙ & $\vec{\alpha} \tilde{\sim}$ & ప3 \\
\hline & 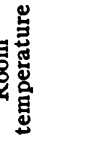 & \multicolumn{2}{|c|}{\begin{tabular}{ll}
0 & 0 \\
0 & $a$ \\
0 & \multirow{1}{*}{}
\end{tabular}} & \multicolumn{2}{|c|}{$\begin{array}{l}0 \\
\infty \\
+1 \\
\text { in }\end{array}$} & \multicolumn{2}{|c|}{$\begin{array}{l}\stackrel{0}{\circ} \\
\vec{\jmath} \\
\stackrel{0}{0} \\
.\end{array}$} & \multicolumn{2}{|c|}{\begin{tabular}{c}
0 \\
$\stackrel{a}{1}$ \\
\multirow{1}{1}{} \\
$\infty$ \\
$\infty$
\end{tabular}} & \multicolumn{2}{|c|}{$\begin{array}{l}\stackrel{0}{0} \\
\stackrel{1}{I} \\
\stackrel{+}{+}\end{array}$} & \multicolumn{2}{|c|}{$\begin{array}{l}\vec{n} \\
\vec{d} \\
\dot{0} \\
\dot{m}\end{array}$} \\
\hline & 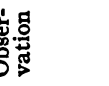 & \multicolumn{2}{|c|}{ 오 } & \multicolumn{2}{|c|}{$\stackrel{n}{m}$} & \multicolumn{2}{|c|}{ ๓ี } & \multicolumn{2}{|c|}{$\hat{n}$} & \multicolumn{2}{|c|}{$\overrightarrow{\bar{n}}$} & \multicolumn{2}{|c|}{$\overrightarrow{\widetilde{⿵}}$} \\
\hline & 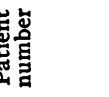 & \multicolumn{2}{|c|}{$m$} & \multicolumn{2}{|c|}{ 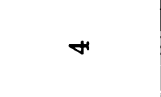 } & \multicolumn{2}{|c|}{ in } & \multicolumn{2}{|c|}{ in } & \multicolumn{2}{|c|}{ in } & \multicolumn{2}{|c|}{ in } \\
\hline
\end{tabular}


A complete summary of four observations on Patient 1 is given in Table 6. Suction and pressure were applied to the left extremity in two instances and to the right extremity in two. The digits exposed to suction and pressure became warmer by 7.4 to $10.5^{\circ} \mathrm{C}$. while the control digits became warner by 1.1 to $6.0^{\circ} \mathrm{C}$. though exposed to a warmer environmental temperature. This greater elevation of temperature in the extremity exposed to suction and pressure indicates an increase in cutaneous blood flow which can not be ascribed to ordinary vasodilatation since, as mentioned above, the removal of vasoconstrictor tone by two methods failed to elevate skin temperature.

Patient 2 (Table 6), a white male, aged 58, was a mild diabetic who had, for the previous two years, complained of coldness and blueness of both feet with dry, indolent ulceration of the left great toe and more recently of the right heel. Examination showed a blood pressure of $172 \mathrm{~mm}$. $\mathrm{Hg}$ systolic and $90 \mathrm{~mm}$. $\mathrm{Hg}$ diastolic, with retinal sclerosis and, by $\mathrm{x}$-ray, considerable sclerosis of the vessels of the lower extremities. Dorsalis pedis and posterior tibial pulsations were absent in both feet. In the dependent position both feet were markedly cyanotic. At a room temperature of 17 to $18^{\circ} \mathrm{C}$. both forearms were immersed in warm water (42.0 to $45.0^{\circ} \mathrm{C}$.). The toes of both feet cooled steadily during the usual 35 minute period of immersion, showing no vasodilator response whatever. This was taken to indicate a high grade of organic arterial obstruction in both lower extremities.

At a room temperature (Table 6) of 17 to $18^{\circ} \mathrm{C}$. the right extremity was placed in the aluminium box, the left in the warmer control box. Immersion of one forearm in warm water produced no change in the skin temperatures of the lower extremities. Suction and pressure were then applied to the right lower extremity for 41 minutes. During this period the temperatures of the right first and third toes rose 3.7 and $3.9^{\circ} \mathrm{C}$. respectively, while the temperatures of the left first and third toes in the warmer (by over $1^{\circ} \mathrm{C}$.) control box rose 1.7 and $1.3^{\circ} \mathrm{C}$. respectively. The right extremity became warmer than the surrounding air, while the left, or control extremity, remained slightly cooler than the surrounding air throughout the observation, warming very slowly, however, as air temperature in the control box was elevated to keep it above that in the aluminium box.

Patient 3, a white male, aged 32, had been for several years under treatment for rheumatic fever (inactive) with mitral stenosis and auricular fibrillation (compensated). He complained of blueness and coldness of both feet, particularly of the right, with typical intermittent claudication in the right leg - all of two months' duration. Posterior tibial and dorsalis pedis artery pulsations were felt in the left foot. The right dorsalis pedis artery pulsated normally but the right posterior tibial pulsation could not be felt. Three cc. of 2 per cent novocaine were injected near the right 
posterior tibial nerve and the right first, third and fifth digits, originally $22.1,21.6$, and $20.5^{\circ} \mathrm{C}$. warmed to $32.5,32.9$ and $31.7^{\circ} \mathrm{C}$. respectively in a room at 19 to $20^{\circ} \mathrm{C}$. This response indicated that the symptoms were due primarily to arterial spasm.

At a room temperature of 14.9 to $16.0^{\circ} \mathrm{C}$. the right lower extremity was placed in the aluminium box, the left lower extremity in the control box. Suction and pressure were applied to the right lower extremity for 56 minutes. At the beginning of this period the right first and third toes were slightly cyanotic and slightly cooler than the left toes. During the period of pressure changes the right digits became definitely pink and warmer by 12.3 and $5.7^{\circ} \mathrm{C}$. while the left digits became warmer by 2.8 and $2.1^{\circ} \mathrm{C}$., the latter being exposed in the control box to an average air temperature over $2^{\circ} \mathrm{C}$. higher than that in the aluminium box. The right digits, exposed to suction and pressure, became conspicuously warmer than the surrounding air while the left digits originally cooler than the surrounding air remained so throughout the observation.

Patient 4 (B1), a white male, aged 46, was a diabetic whose right second toe had previously been amputated on account of gangrene. The tip of the right third and fourth toes had been the seat of gangrenous ulcers which healed with rest and local heat. On two occasions immersing the forearms in warm water failed to produce vasodilator response, indicating marked organic obstruction, verified in the left foot by the absence of vasodilatation after anesthetizing the left posterior tibial nerve. This patient's history has already been summarized in another paper (3).

The right lower extremity was placed in the aluminium box, the left in the control box. The temperature of the left foot was higher than that of the right, both extremities being relatively warm because the patient had been brought straight from the ward where the feet were kept constantly under a warm cradle. Suction and pressure were applied to the right lower extremity for 27 minutes and during this period the right first and third digits became 4.4 and $3.6^{\circ} \mathrm{C}$. warmer while the corresponding digits of the other foot became 0.7 and $0.4^{\circ} \mathrm{C}$. cooler respectively, though the latter were exposed to environmental temperature over $2^{\circ} \mathrm{C}$. higher. The right digits, originally cooler than the left, became, during suction and pressure, warmer than the left.

Patient 5, a white Hebrew male, aged 58, suffered from thromboangiitis obliterans with coldness and cyanosis of the right foot as well as typical intermittent claudication in the right leg. The left foot became cold easily but cyanosis and pain were absent.

The posterior tibial pulse was absent bilaterally; the dorsalis pedis pulse was absent on the right but present on the left. Immersing both forearms in warm water on several occasions indicated uniformly that the arteries of the right extremity were organically diseased to a conspicuous degree, while those of the left extremity were less conspicuously affected. The vasomotor index of the right foot was 1.1, that of the left 1.3. 
The observation shown in Figure $7 A$ indicates qualitatively the difference in the temperature responses observed in the lower extremities of this patient when one or two forearms were immersed in warm water. The right lower extremity showed usually a delayed, slight rise in temperature while the left extremity warmed more or less completely. In the

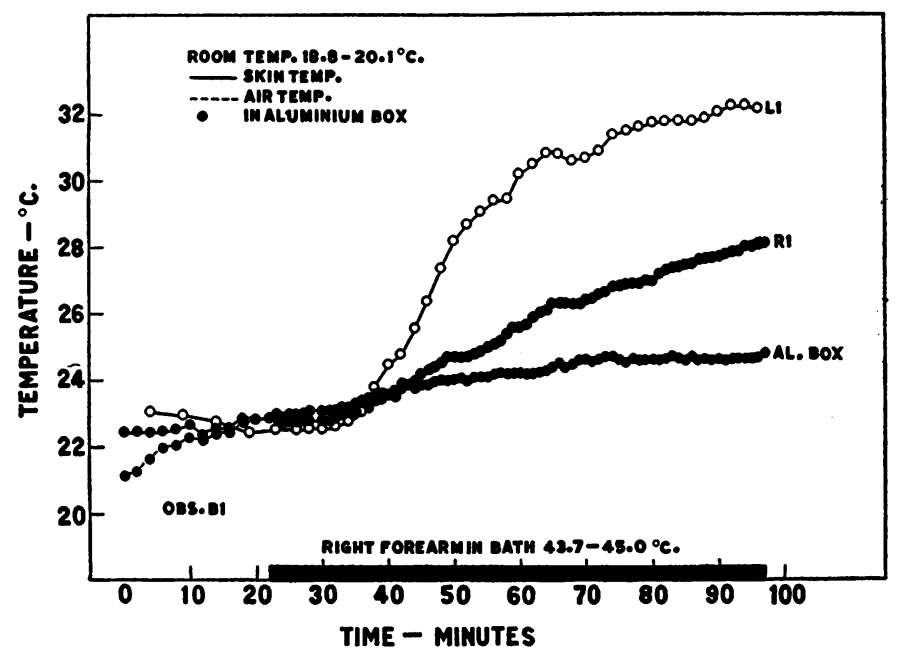

Fig. 7 $A$. Showing Vasodilator Response in the Lower Extremities of Patient 5 during Immersion of One Forearm in Warm Water

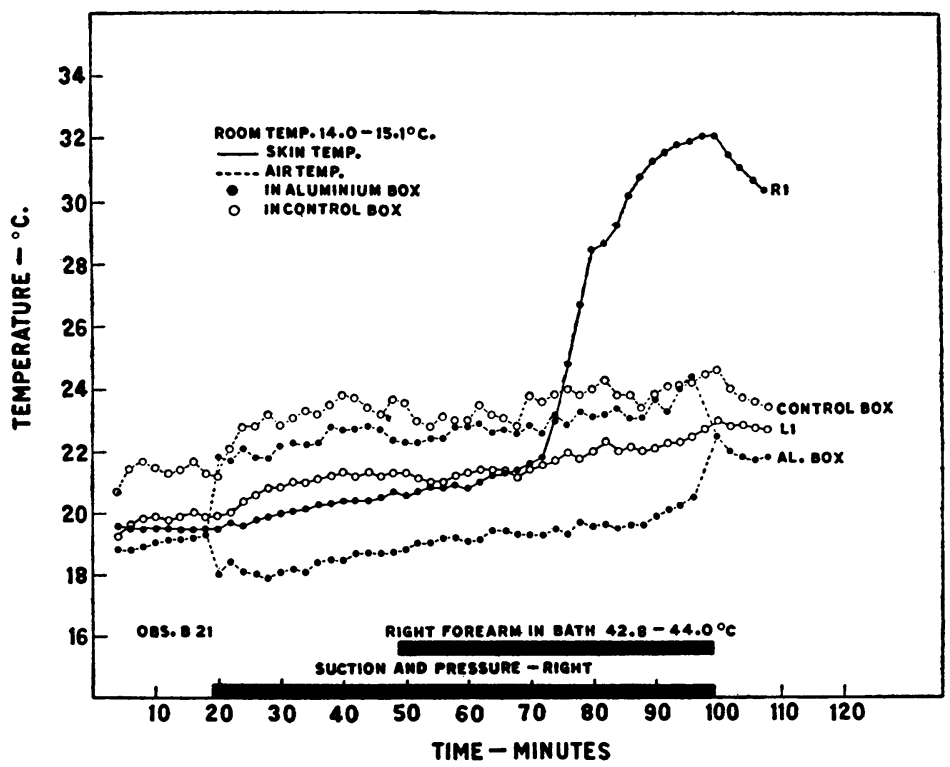

Fig. 7B. Showing Rise in Skin Temperature of the Right Lower Extremity during Application of Suction and Pressure 
observation charted in Figure $7 \mathrm{~A}$ the left extremity was exposed to room air having a temperature of 18.8 to $20.1^{\circ} \mathrm{C}$., the right lower extremity being placed in the aluminium box with an air temperature of approximately $24^{\circ} \mathrm{C}$. Immersing one forearm in warm water was followed by a relatively rapid warming of the left first toe to $32.2^{\circ} \mathrm{C}$. while the right first toe in spite of the higher temperature of the surrounding air warmed more slowly to $28.1^{\circ} \mathrm{C}$. during the same period.

The effects of suction and pressure on skin temperature in this patient are shown in Figure $7 B$. The left and more nearly normal extremity was placed in the warmer control box. The right, more diseased extremity was placed in the cooler aluminium box. Suction and pressure alone failed to change skin temperature appreciably at the relatively low room temperature of 14.0 to $15.1^{\circ} \mathrm{C}$. The right forearm was immersed in warm water and after approximately twenty minutes the temperature of the right first toe rose above that of the left and finally reached $32.1^{\circ} \mathrm{C}$. The left first toe though originally the warmer, and in a warmer environment throughout the observation, remained cooler by $9.5^{\circ} \mathrm{C}$. Four observations on this patient are summarized in Table 6. In each instance the right digits, originally cooler than the left, became warmer than the left during suction and pressure and the ordinary temperature relationship shown in Figure $7 A$ in response to heat alone was reversed.

If all the figures in Table 6 are summarized in the form of averages it is found that the digits exposed to suction and pressure became warmer by $7.1^{\circ} \mathrm{C}$. while the control digits became warmer by $1.9^{\circ} \mathrm{C}$. although the latter were in a warmer environment. From these averages and from the individual observations it appears that applying suction and pressure increases the flow of blood to the digits even in the presence of organic arterial disease. The findings in Patients 1, 2 and 4 indicate that suction and pressure may increase blood flow though removal of vasoconstrictor tone fails to do so.

\section{Skin color during suction and pressure}

In this paper emphasis has been laid upon changes in skin temperature since they seemed theoretically to provide the most objective and convincing means of identifying changes in arterial blood flow. Skin color was also observed but drawing definite conclusions on this basis alone did not seem justifiable for several reasons. When the extremities are cold, as emphasized by Lewis (6) in his studies of Raynaud's disease, cyanosis develops relatively slowly. As regards blood flow, redness or cyanosis of the skin with surface temperature of $30^{\circ} \mathrm{C}$. has an entirely different significance from the same grade of redness or cyanosis at a surface temperature of $20^{\circ} \mathrm{C}$. Moreover, skin color depends to a certain extent, as shown by Goldschmidt and Light (7), upon the amount of blood in the skin. Therefore, diminution of cyanosis was regarded as corroborative but not 
definitive evidence of marked change in blood flow. It was rather difficult to read colors accurately through the glass cover of the box, since the glass itself changed slightly the depth and the tint of the color observed. Nevertheless, in many observations it was possible under favorable conditions to identify convincing changes in skin color.

When the extremities of the normal subjects were cold and when peripheral vasoconstrictor tone was high, as in the shivering subject, little or no change in skin color could be detected during the changes in pressure -corresponding to the occasional absence of skin temperature changes under these conditions. Apparently when vasoconstrictor tone is high the amount of blood accommodated by the minute vessels of the skin is relatively small and pressure variations, as described above, had, in some instances, little influence on total blood flow. The veins were usually small and were not prominent even during suction.

When vasoconstrictor tone was reduced by immersing one forearm in warm water the color changes in the lower extremities became very pronounced. During suction skin color changed from its normal pink to a deep red tint, and at the end of the suction period the skin was more or less engorged. The veins were large and when vasodilatation was complete in a normal subject sensations of tightness, fullness and more rarely tingling occurred. The sensations were those usually accompanying passive congestion but were by no means as severe as the sensations produced during passive congestion by means of a pneumatic armlet inflated to a pressure of 60 or $80 \mathrm{~mm}$. Hg. As soon as suction ended and pressure began the sensation of engorgement disappeared. The skin previously dark red in color became quite pale or light pink in color, the tips of the toes tending to retain their deep color longer than any other part of the foot. The veins collapsed more or less completely; if they did not diminish in prominence during pressure it indicated that the cuff surrounding the thigh was too tight.

In normal subjects the amount of cyanosis present in the cold extremity was extremely slight so that definite comparisons of skin color during suction were difficult. It was repeatedly noticed and recorded, however, that the slight cyanosis had disappeared after the period of suction and pressure. More pronounced changes in skin color were observed in patients with peripheral vascular disease.

The digits of the lower extremities of Patient 1 were usually moderately cyanotic. Immersing both forearms in warm water failed to modify skin color perceptibly. On the contrary, during the period when vasodilator tone was being reduced the color of the skin of the lower extremities gradually became more cyanotic. In Observation B11 suction and pressure were applied to the right extremity and the skin color of the right first digit was slightly less cyanotic than that of the left first digit at the end of the observation. In Observation B13 the application of suction 
and pressure to the left extremity was accompanied by a lesser cyanosis in the left first and third digits as compared to the right first and third digits.

In Patient 2 immersing both forearms in warm water produced neither a lessening of cyanosis nor an increase in skin temperature in the lower extremities. Negative and positive pressures caused the right first digit and the dorsum of the right foot to become definitely pink though both were cyanotic before the pump was started. An area of skin over the first metatarso-phalangeal joint though deeply cyanotic before the application of suction and pressure was normal in color at the end of the observation, while the corresponding area in the left foot was still cyanotic.

In Patient 3 the right first digit, moderately cyanotic before the application of suction and pressure, was definitely pinker at the end of the observation. In Patient 4 no color observations could be made due to unsatisfactory light.

In Patient 5 the skin color of the right digits, originally moderately cyanotic, changed but little when vasoconstrictor tone was reduced by immersing both forearms in warm water. In four observations (B2, B7, $\mathrm{B} 17$ and $\mathrm{B} 21$ ) the color of the right digits became brighter, changing from a moderate or marked cyanotic tint before suction and pressure to a normal tint or, at most, a slightly cyanotic tint at the end of the suction and pressure period.

The observations on skin color corroborated the more objective and definite skin temperature studies, both indicating an increased blood flow during the application of alternate suction and pressure.

\section{DISCUSSION}

The desirability of increasing local blood supply in certain medical and surgical conditions involving the extremities has long been recognized. As an early attempt in this direction the application of a bandage proximal to the lesion was, according to Bier (8), first described by Paré (9). This method was later used chiefly for treating ununited fractures by Nicoladoni (10), Thomas (11), and Helferich (12) but has been more recently revived and extended by Bier (8). While such passive congestion produces venous engorgement and increases the amount of blood trapped in the vessels distal to the bandage it does not increase, but really reduces, total blood flow if congestion is extreme, as shown by the calorimetric measurements of Stewart (13).

Negative pressure was apparently first extensively used in 1829 by Junod (14) who constructed a series of "pneumatic chambers" designed to accommodate one or more extremities or even most of the body. Under the name of "hemospasie" negative pressure was used enthusiastically to treat almost every form of local or systemic disease. Junod used negative pressures amounting to between $1 / 3$ and $1 / 7$ atmosphere over more or less 
prolonged periods. This energetic procedure resulted in intense sensations of tension in the skin, numbness, prickling, and extensive subcutaneous hemorrhages. Junod also mentioned the use of positive pressure but in the monograph published in 1875 only negative pressure is discussed in detail.

Bier placed the extremities in glass vessels with a rubber cuff around the base of the limb, and evacuated the air by means of a small hand pump. He attempted to produce engorgement of the skin without hemorrhages. Air was removed slowly to produce the desired grade of congestion which was maintained for several minutes. Air was then allowed to enter the vessel restoring atmospheric pressure and after an interval of twenty seconds to several minutes the pressure was again reduced, the procedure being repeated for periods of 20 to 30 minutes. The changes in skin color were stated by Bier to be similar to those produced by simple venous congestion including cutaneous hemorrhages in small numbers. According to Bier the apparatus thus applied merely produced "stasis hyperemia" due to hindrance of the venous return flow since the cuff acted as a rubber bandage during the application of negative pressure.

These early attempts to modify circulation in the extremities by the use of negative pressure were not of the type which would be expected to produce significant increase in arterial blood flow through rigid vessels, and no convincing objective evidence of increased blood flow was given by these authors. If suction is applied to the skin the peripheral fall in blood pressure and the rate of blood flow into the part will theoretically be increased only during the period which is required to fill the capillaries and venules with blood. This period is relatively short in duration. Lewis (5) observed that when a pneumatic cuff was wrapped around the upper arm and inflated, venous pressure, measured directly, equalled the pressure in the pneumatic cuff within approximately 45 seconds. The effect of negative pressure on the entrance of arterial blood into the extremity would therefore last not longer than 45 seconds and even so would be considerably diminished during the latter part of this period. Thereafter, in the absence of vasodilatation, no matter how long negative pressure were applied the rate of blood flow would not be increased above that present prior to the application of negative pressure.

In the observations described in the present paper alternate suction and pressure were used in an attempt to increase the total flow of blood through the digits with as little cutaneous engorgement as possible. Negative pressure was applied for a brief period to produce relatively incomplete filling of the capillary and venous bed, since excessive distention of the minute vessels would not only produce discomfort but would also diminish the effect exerted by the external negative pressure on the peripheral drop in blood pressure.

Various time intervals were used in normal subjects. It was found that 25 seconds of negative pressure $(120 \mathrm{~mm} . \mathrm{Hg})$ produced a perceptible 
tightness of the skin when vasoconstrictor tone was reduced by warming the forearms. When vasodilatation was not extreme 25 seconds of negative pressure produced little sensation of distention. In all of the observations on normal subjects and patients discomfort has been negligible and no hemorrhages into the skin have been observed. A negative pressure of $120 \mathrm{~mm} . \mathrm{Hg}$ would undoubtedly produce cutaneous hemorrhages if it were permitted to act for a long time. However, during periods of 25 seconds the veins and capillaries are not maximally distended and consequently the vessel walls are not stretched to a point where hemorrhages are apt to occur. Moreover, in patients with organic arterial obstruction distention would occur at a later period than in normal subjects whose arteries are still of normal calibre.

The cuff congests the leg slightly and in itself tends to keep the veins distended. Hence brief periods of pressure were used to empty the peripheral vessels and to provide an adequate reservoir for the accommodation of the blood drawn in by the succeeding period of suction, an essential point theoretically in favoring an increase in the rate at which arterial blood enters the capillaries and veins. Simple intermittent suction with rest periods would probably be less efficient since $(a)$ the congestion produced by the cuff would not be overcome and $(b)$ emptying would be slow and incomplete. The importance of diminishing vasoconstrictor tone has already been considered.

Inspection of the tables will show that occasionally skin temperatures were lower than the temperature of the air in the boxes. At the outset the air in the boxes had the same temperature as room air. As soon as the boxes were closed the air surrounding the extremities began to warm, presumably due to radiation from the warmer proximal portions of the extremity enclosed within the boxes. Nevertheless, the temperature of the digits exposed to suction and pressure rose well above environmental temperature.

The possibility that the rise in skin temperature was due purely to physical forces, incident to changing air pressure can be ruled out by inspection of Figures $4 A, 4 B, 6 C$, and $7 B$. If the elevation of skin temperature had been due to condensation of moisture, or to heat produced during compression of the air within the box the skin temperature would have begun to rise in every instance as soon as the pressure variations were used. In these four observations as well as many others skin temperature did not change, in spite of suction and pressure, until vasoconstrictor tone was diminished. Moreover, such physical effects could not explain the elevation of skin temperature above the environmental temperature. A bottle covered with moist gauze, the latter to simulate moist skin, cooled slightly in the aluminium box during the prolonged application of positive and negative pressure. These observations are believed to rule out artefacts due to purely physical factors. 
Concerning the clinical value of this procedure nothing can be said except that it may offer a method of increasing blood flow temporarily in patients in whom even the total removal of vasoconstrictor tone does not increase blood flow. Used with caution it may assist in delaying or preventing the progress of ulceration or threatened gangrene in those cases of peripheral vascular disease in which obliterative structural disease has advanced to such a stage that the arterial vessels are no longer able to dilate. Whether the effects of suction and pressure on blood flow are entirely temporary or. whether they may favor the development of more efficient collateral circulation can only be determined by a series of carefully controlled clinical observations.

\section{SUMMARY}

As an application of Poiseuille's law the effects of alternate suction and pressure on the flow of blood through the lower extremities were studied in normal subjects and in patients with peripheral vascular disease. Increased rate of blood flow was identified by rise in skin temperature under carefully controlled conditions.

In a circulation schema it was found that alternate suction and pressure increased by 45 to 78 per cent the rate at which fluid flowed past an obstruction.

In normal subjects alternate suction and pressure $(a)$ diminished the rate of cooling of an extremity originally warm and $(b)$ in the majority of instances caused an originally cold extremity to become conspicuously warmer. Suction and pressure sometimes failed to affect blood flow in the cold extremity but, as soon as vasoconstrictor tone was diminished slightly, blood flow was conspicuously and preferentially increased in the extremity exposed to external pressure variations.

The vasodilator response to warming one forearm was studied in normal subjects with and without the use of external pressure changes. Alternate suction and pressure caused the vasodilator response to appear earlier and the final skin temperatures reached were definitely higher in the extremity exposed to external pressure changes.

In patients with peripheral vascular disease alternate suction and pressure increased blood flow even though organic obstruction had advanced to such a stage that no rise in skin temperature was obtained when vasoconstrictor tone was completely abolished by immersing both forearms in warm water or by anesthetizing the posterior tibial nerve.

The effects of suction and pressure on cyanosis associated with peripheral vascular disease are briefly discussed.

To obtain maximal effects on blood flow it is apparently advisable to have (1) relatively brief periods of suction, (2) intermittent, brief periods of pressure and (3) diminished vasoconstrictor tone. 


\section{BIBLIOGRAPHY}

1. Landis, E. M., and Gibbon, J. H., Jr., J. Clin. Invest., 1933, xii, 105. The Effects of Temperature and of Tissue Pressure on the Movement of Fluid through the Human Capillary Wall.

2. Lewis, T., and Grant, R., Heart, 1925, xii, 73. Observations upon Reactive Hyperaemia in Man.

3. Gibbon, J. H., Jr., and Landis, E. M., J. Clin. Invest., 1932, xi, 1019. Vasodilatation in the Lower Extremities in Response to Immersing the Forearms in Warm Water.

4. Lewis, T., and Pickering, G. W., Heart, 1931, xvi, 32. Vasodilatation in the Limbs in Response to Warming the Body; with Evidence for Sympathetic Vasodilator Nerves in Man.

5. Lewis, T., Heart, 1924, xi, 109. The Force Exerted by the Minute Vessels of the Skin in Contracting.

6. Lewis, T., Heart, 1929-30, xv, 7. Experiments Relating to the Peripheral Mechanism Involved in Spasmodic Arrest of the Circulation in the Fingers: a Variety of Raynaud's Disease.

7. Goldschmidt, S., and Light, A. B., Am. J. Physiol., 1925, 1xxiii, 173. A Cyanosis, Unrelated to Oxygen Unsaturation, Produced by Increased Peripheral Venous Pressure.

8 Bier, A. Hyperemia as a Therapeutic Agent. (Translation by G. M. Blech), 1915.

9. Paré, d'A. Oeuvres Complètes. (Translation of Malgaigne, 1840, Vol. II, Book XIII, p. 346.) Ballieré, Paris, 1840.

10. Nicoladoni, K., Wien. med. Wchnschr., 1875, xxv, 81, 109 and 124 . v. Dumreicher's Methode zur Behandlung drohender Pseudarthrosen.

11. Thomas, H. O., Contributions to Surgery and Medicine. Part VI, Lewis, London, 1886.

12. Helferich, Arch. f. klin. Chir., 1887, xxxvi, 873. Ueber künstliche Vermehrung der Knochenbildung.

13. Stewart, G. N., Arch. Int. Med., 1917, xix, 335. The Effect of Bandaging of the Legs on the Rate of Blood Flow in the Feet.

14. Junod, V. I., Traité théorique et pratique de L'Hémospasie. Masson, Paris, 1875. 